\title{
WestVirginiaUniversity
}

THE RESEARCH REPOSITORY @ WVU

Graduate Theses, Dissertations, and Problem Reports

2011

\section{Creating Reporter Systems within Drosophila melanogaster}

\author{
Ashley Elizabeth Banks \\ West Virginia University
}

Follow this and additional works at: https://researchrepository.wvu.edu/etd

\section{Recommended Citation}

Banks, Ashley Elizabeth, "Creating Reporter Systems within Drosophila melanogaster" (2011). Graduate Theses, Dissertations, and Problem Reports. 3352.

https://researchrepository.wvu.edu/etd/3352

This Thesis is protected by copyright and/or related rights. It has been brought to you by the The Research Repository @ WVU with permission from the rights-holder(s). You are free to use this Thesis in any way that is permitted by the copyright and related rights legislation that applies to your use. For other uses you must obtain permission from the rights-holder(s) directly, unless additional rights are indicated by a Creative Commons license in the record and/ or on the work itself. This Thesis has been accepted for inclusion in WVU Graduate Theses, Dissertations, and Problem Reports collection by an authorized administrator of The Research Repository @ WVU. For more information, please contact researchrepository@mail.wvu.edu. 


\title{
Creating Reporter Systems within Drosophila melanogaster
}

\author{
Ashley Elizabeth Banks
}

\author{
Thesis \\ Submitted to the Eberly College of Arts and Sciences \\ at West Virginia University \\ in partial fulfillment of the requirements \\ for the degree of \\ Master of Science \\ in \\ Cellular and Molecular Biology
}

Committee Members:

Clifton Bishop, Ph.D., Chair

Ashok Bidwai, Ph.D.

Daniel Panaccione Ph.D.

Department of Biology

Morgantown, West Virginia

2011

Key words: $E(s p l) C$, Phosphorylation, Epigenetics, CK2, Fluorescent proteins 


\section{Abstract \\ Creating Reporter Systems within Drosophila melanogaster Ashley Elizabeth Banks}

The objective of these projects was to generate two fluorescently based systems within Drosophila melanogaster for the advancement of molecular research. The first project was aimed to create fluorescent phosphomimetic constructs of $m 8$, a regulator in eye formation. The second project was to create a fluorescent visual marker for heterochromatic gene silencing in Drosophila. Proper formation of the eye requires that only one cell from a group of equipotent cells assumes a neural fate (the R8 cell). The cells surrounding the R8 cell are prevented from assuming this outcome through a process known as lateral inhibition. Lateral inhibition uses the regulation of proteins from the Enhancer of split complex $E(\mathrm{spl}) C$, to down regulate the neural protein, Atonal. The functionality of a specific $\mathrm{E}(\mathrm{spl})$ protein, $\mathrm{M} 8$, is regulated by phosphorylation by $\mathrm{CK} 2$ at a specific site within the phosphorylation domain of M8. It was the goal of this project to create fluorescently labeled phosphomimetic variants of M8 with aspartic acid and alanine substitutions at key phosphorylation sites (the CK2 phosphorylation site and all four phosphorylation sites within the M8 phosphorylation domain). These constructs were used to generate preliminary data in a Drosophila Expression System. The initial data indicated that

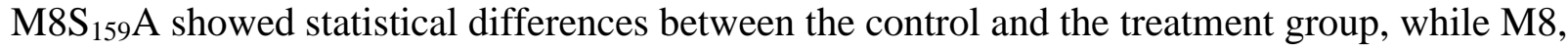

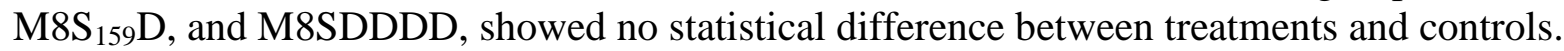
The location of these constructs in Schneider 2 cells suggested that M8 and M8S ${ }_{159}$ A proteins were at times located in the nucleus, while the other phosphomimetic variants were restricted to the cytoplasm. This project generated a solid foundation of data collection methods and gave some insight into the location of M8 that can give rise to future studies within this system.

The second project was aimed at creating a fluorescent marker for an epigenetic phenomenon known as Position Effect Variegation (PEV) within Drosophila. PEV is caused by the relocation of a gene close to, if not adjacent to heterochromatin. When in close proximity, the heterochromatin can spread to silence the gene in some cells, rendering the gene silent; while failing to spread in others, allowing for expression resulting in a variegated phenotype within Drosophila. Male flies with a miniwhite gene adjacent to Gal4/UAS driven Yellow Fluorescent Protein were mutated in hopes of causing a translocation or inversion which would bring the fluorescent marker in close proximity to heterochromatin to observe epigenetic silencing. Although no variegated flies were found, this tool would serve as an effective marker to visually observe, using different UAS drivers within Drosophila, where PEV is occurring spatially and at what developmental time points within the fly as well. Such a variegating mutant would provide a molecular tool for future research on how CK2 and other modifiers of PEV act within the cascade of epigenetic changes within Drosophila. 


\section{Acknowledgements}

There are many people that I would like to thank for their guidance, support, hard-work, generosity and dedication to me throughout the duration of my Master's program here at WVU.

First and foremost, I would like to thank my advisor Dr. Clifton Bishop for his willingness to guide me through my tenure here. Through the high points and low points, it has been truly a privilege to be a student for him. Secondly, I would like to thank the other members of my committee, Dr. Ashok Bidwai, and Dr. Daniel Panaccione for their commitment to me as a student, influences on me as a biologist and for their time and support.

I am very appreciative of my fellow lab member's Stephanie Young, Tiffany Smith, Swati Banerjee, and Bia Vianna for their direction and friendship during my time here at WVU. I would also like to recognize the members from Dr. Bidwai's lab, Anasua Bose, Bhaskar Kahali, Mohna Bandyopadhyay, Lucas Jozwick, and Adam Majot who contributed greatly to my success. Also I appreciate Sophia Zhang's guidance on the care and techniques of the S2 cell line. I also would like to thank the entire Biology department for their management and direction during my time here.

Finally I could not have completed this without the support network of my family and friends. I would like to personally thank my fiancé, Jes for inspiring me to always do my best, to strive to surpass the goals I set for myself and being the rock in my life. Thank you to my best friend Ashley Neal who helped me pursue my dreams and stood by me throughout. And finally I would like to thank my family who always supported me and motivated me so I could do anything that I set my mind to, thank you for being so loving and encouraging. I can honestly say I wouldn't be where I am today without all these special people in my life. 


\section{Table of Contents}

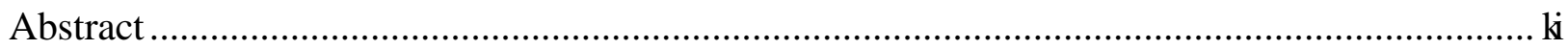

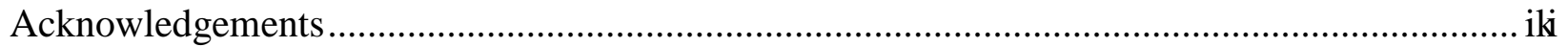

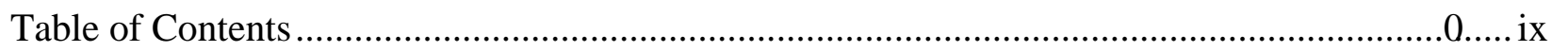

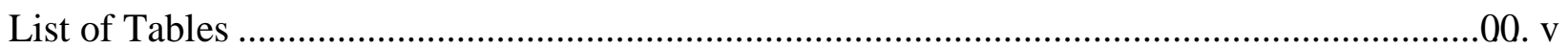

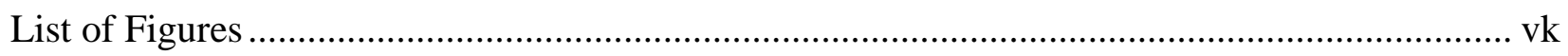

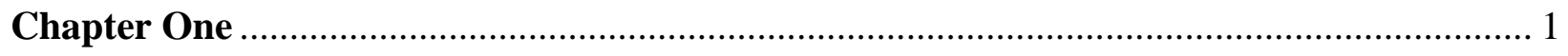

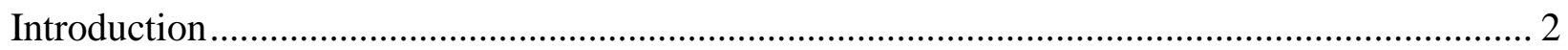

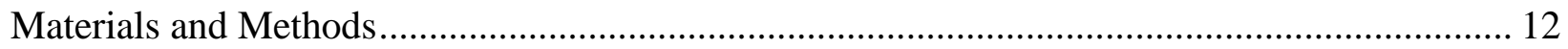

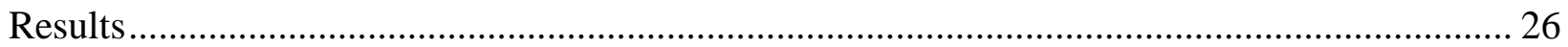

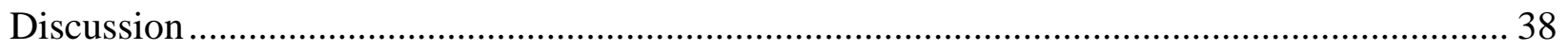

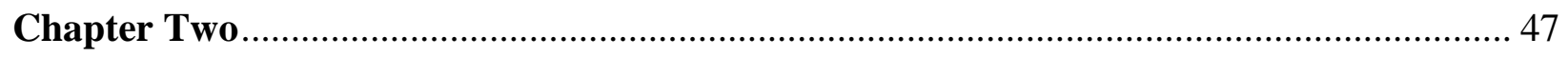

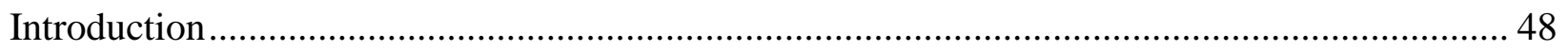

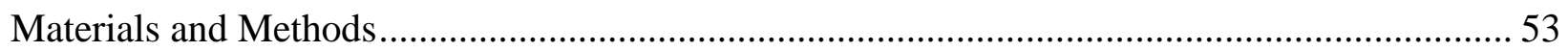

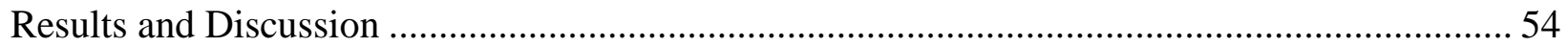

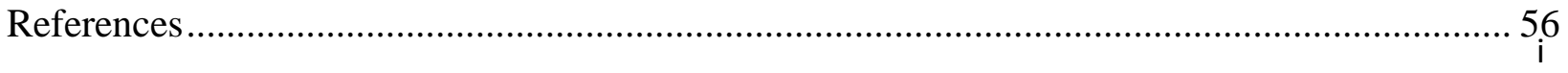




\section{List of Tables}

1-1 - Site Directed Mutagenesis Primers $\quad 12$

1-2 - Co-transfection Table of Reagents 19

1-3 - Localization Study of M8, M8SA, M8SD, M8SDDDD 36 


\section{List of Figures}

1-1 - Notch Signaling During Lateral Inhibition 4

1-2 - M8 Structural Domains

1-3 - Site Directed Mutated CFP-m8-YFP Constructs 14

1-4 - Data Collection of Mean Intensity of Fluorescence in One Z-Position 22

1-5 - Data Collection of Mean Intensity of Fluorescence 22

1-6 - Data Collection of Intensity of Fluorescence in One Z-Position for the Nucleus and Total Cell $\quad 24$

1-7 - Mean Intensity of Fluorescence Data Collection 24

1-8 - Cellular Growth Curves for Differing Environmental Conditions 27

1-9 - Cell Viability at Differing Environmental Conditions 28

1-10 - CFP-m8S ${ }_{159} A-Y F P$ Co-transfection Fluorescence Values 31

1-11 - CFP-m8-YFP Co-transfection Fluorescence Values 32

1-12 - CFP-m8S ${ }_{159} D$-YFP Co-transfection Fluorescence Values 33

1-13 - CFP-m8SDDDD-YFP Co-transfection Fluorescence Values 34

1-14 - Combined Co-transfection Data 35

1-15 - Differences in Compartmentalization of Fluorescence 37

2-16 - Mottled Phenotype in Drosophila 49

2-17 - Gene Silencing Due to Position Effect Variegation 50 
Chapter One- Creating an In Vivo Reporter System to Observe the Location of M8 Phosphorylation in S2 Cells 


\section{Introduction}

The initiation of the correct neural cell spatial patterning and growth during embryogenesis is a crucial component of the proper developmental stages in an organism's life. The Delta-Notch signaling pathway has been studied and identified as a regulator of neurogenesis within many species, including Drosophila melanogaster. This pathway is highly conserved, playing a significant role in the development of organisms as diverse as nematodes and humans. By studying this vital pathway in Drosophila it will help give insight into understanding the complete process of neural cell selection in vivo.

The formation of sensory organ precursor cells (SOP) within the Drosophila eye provides an excellent system for studying the Delta-Notch signaling pathway. Formation of 750-800 patterned ommatidia, each containing 8 photoreceptors is determined by numerous regulators and pathways. The establishment of the formation of the eye begins with the initiation of a morphogenetic furrow (MF) which moves across the eye field beginning at the posterior edge of the eye and moving anteriorly within the eye field. This MF moves in stages across the eye, containing stage 1 , stage $2 / 3$, and stage 4 . Once the MF has passed, the initiating photoreceptor cell, R8, is established and is able to recruit the other photoreceptor cells to form the correct patterning of the ommatidia within the compound eye. The organization of the remaining photoreceptor cells and other R8 cells would not form correctly without the initial establishment of R8 cells (Frankfort and Mardon, 2002).

In wild type Drosophila, the selection of a cell to become a neural cell versus a nonneural cell is largely due to the level of activity of a neural gene named atonal. This protein regulates the neural selection of a cell and is regulated in a biphasic mechanism that is not fully understood (Baker, 2004). It is known that within and just anterior to the furrow, proteins that 
regulate Atonal initiate the eye formation cascade of events. These proteins that help regulate Atonal are named Hedgehog (Hh), and Decapentaplegic (Dpp). In stage 1, Atonal is actively being expressed due to the activation by Hedgehog and Decapentaplegic. Once stage 1 of the furrow passes through the eye field, Atonal activity is upregulated using a 5' autoregulatory enhancer found within atonal. In stage $2 / 3$ of the furrow, a protein named Scabrous is secreted and diffuses away from the source. Scabrous is transiently expressed in intermediate groups $(\sim 10$ cells clustered in a patterned arrangement) of cells once the furrow passes. Scabrous helps establish the proper spatial organization of the surrounding $\mathrm{R} 8$ cells keeping them at patterned distances from one another (Frankfort and Mardon, 2002).

In stage $2 / 3$ of the $\mathrm{MF}$, intermediate groups (also known as proneural clusters) are expressing atonal, the neural precursor gene. Of these 10 cells in the proneural cluster, one distinguishes itself from the others and becomes a founding $\mathrm{R} 8$ cell. This recognition of the R8 cell is established by the down regulation of Atonal in the neighboring cells. This control of Atonal occurs due to lateral inhibition, which uses the Delta-Notch signaling pathway within the intermediate groups. The R8 neural cell sends out a signal from the Delta ligand to the Notch receptor on the adjacent cells (Giebel and Campos-Ortega, 1997; Greenspan, 1990). This signal down regulates Atonal in adjacent cells, thereby laterally inhibiting the adjacent cells from becoming neural cells. This pathway and the regulatory protein (M8) found within the cascade will be examined in this study. 


\section{Notch signaling during lateral inhibition}

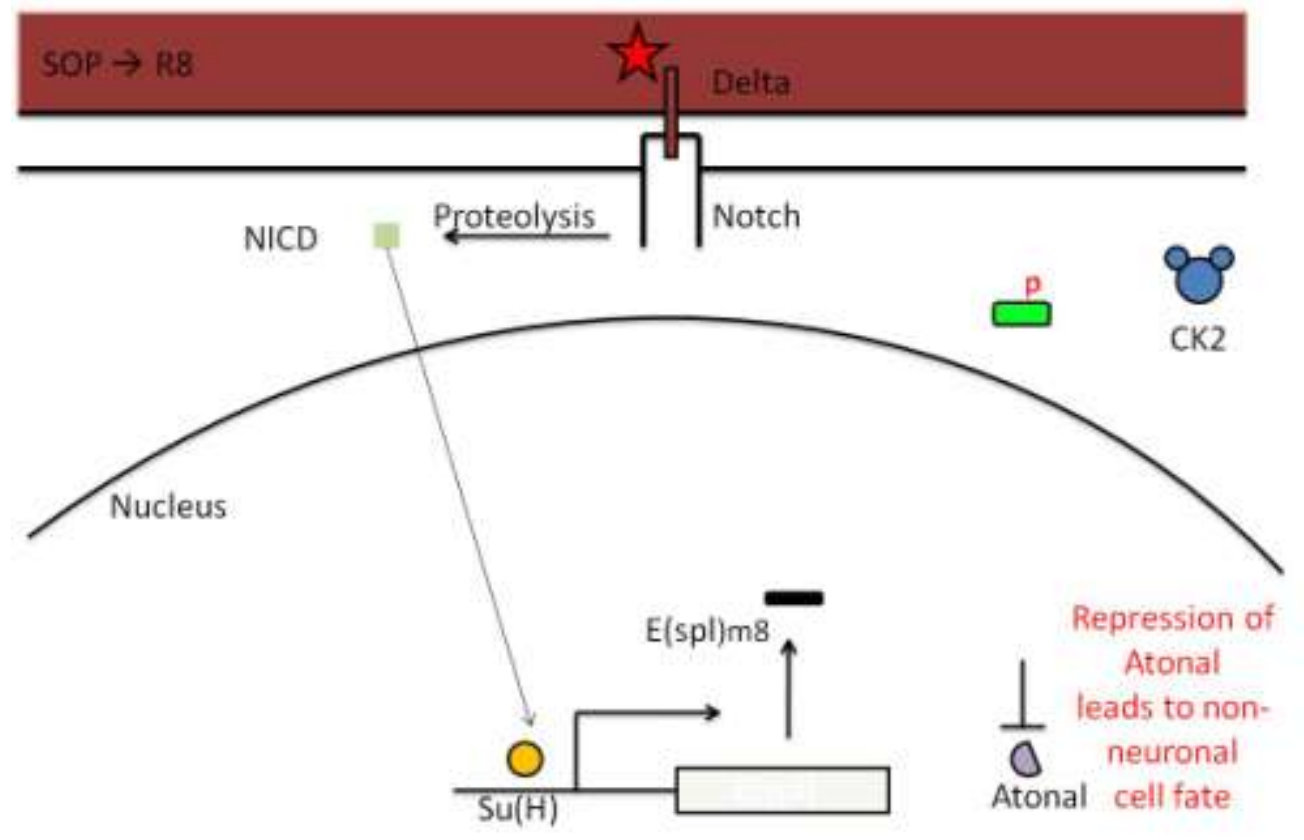

Figure 1: Notch Signaling During Lateral Inhibition- Delta-Notch signaling cascade in Drosophila. Initiation of the cascade begins with an extracellular signal (Delta) that binds to the Notch receptor. Once bound the Notch Intercellular Domain (NICD) is cleaved and relocates to the nucleus. This relocation results in dimerization with $\mathrm{Su}(\mathrm{H})$ and activation of $E(s p l) m 8 . \mathrm{M} 8$ is activated by phosphorylation by CK2 which down regulates Atonal giving rise to a non-neural cell fate in such cells.

The Delta-Notch signaling pathway within Drosophila consists of a Notch receptor that receives an extracellular signal (Delta) from an adjacent cell in the proneural cluster (Figure 1). The Notch receptor is a transmembrane protein containing 2,703 amino acids and upon activation, the intracellular portion of the receptor is cleaved (Fortini et al., 1993). This cleaved portion, which is known as the Notch Intracellular Domain (NICD), translocates to the nucleus and initiates an interaction with a chromosome associated protein Suppressor of Hairless, $\mathrm{Su}(\mathrm{H})$ (Figure 1). This interface, between the NICD and $\mathrm{Su}(\mathrm{H})$ acts as a transcriptional activator of the target genes of Enhancer of split complex $E(s p l) C$, more specifically for this project, $E(s p l) m 8$ (abbreviated $m 8$ ) (Bailey and Posakony, 1995). After translation of M8, this protein is 
phosphorylated in the cell by the protein kinase CK2 and the phosphorylation leads to the corepression of Atonal (Ligoxygakis et al., 1998; Trott et al., 2001). M8 complexes with Groucho which together serve as a co-repressor to help down regulate the expression of Atonal in the cells adjacent to the $\mathrm{R} 8$ cell. The Atonal levels within a cell regulate whether the cell adopts a neural cell fate or a non-neural cell fate. At high levels of Atonal, the cell adopts a neural cell fate, while low levels of Atonal leads to the adoption of a non-neural cell fate (Jan and Jan, 1994). This lateral inhibitory system is expressed in a wide range of tissues and has a wide scope range of activities in vivo depending on the levels of which specific proteins are being expressed (Fischer and Gessler, 2007).

As reviewed by Doroquez and Rebay (2006) within Drosophila, the Notch signaling pathway is crucial in helping initiate neural cell fate within the eye and also aids with correct bristle formation. However, certain abnormalities are observed when this type of cell to cell communication is mis-regulated. For example, having Notch over expression, leads to suppression of the correct eye formation and bristle number, and mis-regulation with Notch underexpression leads to extra bristles and a rough, abnormal eye (Nakao and Campos-Ortega, 1996). This system helps define proper neural cell patterning across species and is therefore critical that more information be learned on this vital pathway.

It is a goal of this project to create phosphomimetic variants of M8, with the anticipation of generating initial data to determine whether phosphorylation at the CK2 site (serine 159), or full phosphorylation of all four phosphorylation sites within M8 (sites 151, 154, 155, and 159) is required for nuclear localization of M8 within a Drosophila Expression System. This determination will help scientists better understand the role of M8 and CK2 within the cascade of 
events that are part of a lateral inhibition pathway. These studies will help determine the correct series of events in the signaling pathway and may serve as a paradigm for similar processes in other species including humans. For example, one protein homologous for M8 in mammals is named Hes6. This family of Hes/Hey proteins resembles the structure and function of the E(spl) proteins within Drosophila (Karandikar et al., 2004; Fischer and Gessler, 2007). Resolving the pathway within Drosophila will give rise to an opportunity for scientists to better understand diseases and illnesses caused by incorrect signaling. Insights gained from these studies may provide a better understanding of human neurological and developmental diseases where Notchbased lateral inhibition is inappropriately implemented, possibly leading to a treatment or cure.

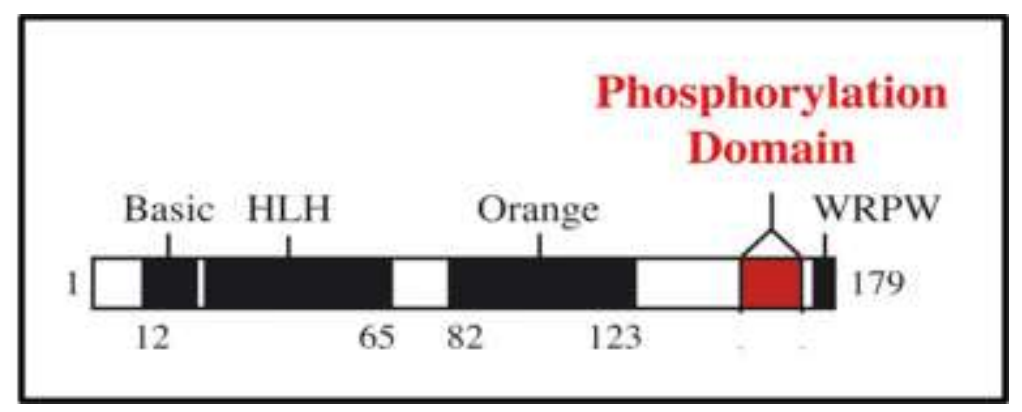

Figure 2: M8 structural domains: The structural domains found within M8 are the Basic domain, the Helix-Loop-Helix domain, the WRPW domain, and the phosphorylation domain. The phosphorylation domain is a key regulator in the level of activity and neurogenesis within Drosophila.

There are seven $E(s p l)$ genes, and of these seven, the one under study, $E(\operatorname{spl}) m 8$ contains certain protein motifs with specific functions. These domains within M8 consist of a basic helixloop-helix domain (bHLH), an Orange domain, a WRPW domain, and a phosphorylation domain (Figure 2). In Drosophila, recruitment of the co-repressor Groucho is mediated through the binding of the WRPW (Tryptophan-Arginine-Proline-Tryptophan) domain and leads to transcriptional co-repression of Atonal (Paroush et al., 1994). The Orange domain within M8 proteins has been implicated to mediate homo and heterodimer formation with other proteins 
containing Orange domains (Akazawa et al., 1992; Sasai et al., 1992). The basic domain in M8 functions as a DNA binding region that regulates gene expression by attaching to DNA at a conserved motif termed the N-box (CACNAG) (Sasai et al., 1992). The regulation of transcription factors and dimerization of other proneural proteins also occurs due to the bHLH domain within the proteins.

The final region of M8 demonstrates a highly conserved phosphorylation domain. The phosphorylation of serines within M8 occurs by four different kinases, Map Kinase (MAPK), CK1, Glycogen Synthase Kinase 3 (GSK3) and CK2 (Lesokhin et al., 1999 and reviewed by Roach, 1991). The phosphorylation domain in M8 contains the $\underline{S} P A \underline{S} G Y H \underline{S}$ sequence which has been implicated as the site of phosphorylation of these four kinases. The first serine within the M8 phosphorylation domain (site 151) is the MAPK phosphorylation site, the second serine (site 154) is the CK1 phosphorylation site, the third serine (site 155) is the GSK3 phosphorylation site and finally the final serine (site 159) is the location of CK2 phosphorylation. It is this CK2 phosphorylation that occurs before the binding and co-repression of Atonal with Groucho (Paroush wt al., 1994). CK2 phosphorylates M8 at the SPXSS-SDXE sequence, which is conserved throughout various species (Trott et al., 2001).

CK2 has been identified as a key player in the modification and regulation of lateral inhibition within Drosophila (Bose et al., 2006). CK2 is a serine/threonine kinase that phosphorylates M8 as well as other proteins within Drosophila. The holoenzyme contains four subunits: two alpha and two beta. The alpha subunit serves as the catalytic subunit, possibly functioning by itself. CK2 is a key regulator in the activation of M8 within the Delta-Notch pathway and it is believed that this activation of M8 functions to elicit lateral inhibition of 
adjacent cells by down-regulating Atonal within the potential neural cell. However, one of the questions that has yet to be resolved is whether CK2 phosphorylation of the M8 protein is required for nuclear localization. While it is hypothesised that the $m 8$ mRNA transcript must leave the nucleus for proper protein translation to occur, and that only phosphorylated M8 can interact with Atonal to repress its function, the exact location of phosphorylated M8 and fully phosphorylated M8 within the cell has yet to be identified. It is therefore the aim of this project to initially create the phosphomimetic $m 8$ constructs in order to determine the location of the phosphorylated and wild type M8 proteins in vivo, with the hopes of generating some preliminary data to answer this question.

Evidence suggests that the non-phosphorylated form of the M8 protein is in a conformation that renders itself autoinhibited. The autoinhibited M8 cannot dimerize or act as a transcription factor. Upon phosphorylation of M8, the autoinhibition is relieved, allowing for binding with other proteins. Therefore, it is believed that the phosphorylation by CK2 elicits a conformational change within M8 (Karandikar et al., 2004). It is a secondary aim of this project to create these $m 8$ constructs with the hopes of being able to resolve if there is a localization or a stability difference in the protein created with alanine in place of the serine in CK2 phosphorylation site when compared to the other aspartic acid and wild type M8 proteins.

The approach that will be used to study cellular localization of M8 will require the use of fluorescently tagging and site-directed mutagenesis (SDM) reactions of the $m 8$ constructs. In the second stage of this project, the constructs will be observed within a Drosophila Expression System to view the location of the proteins within the cell. The SDM reactions use M8 wild type proteins which have been mutated to mimic an always phosphorylated state $(S \rightarrow D)$ using 
aspartic acid, a polar charged amino acid or an unphosphorylatable state $(\mathrm{S} \rightarrow \mathrm{A})$ using alanine, a non-polar amino acid. These mutagenesis reactions occur to the codon in which CK2 phosphorylation occurs at (serine 159) (Trott et al., 2001 and Karandikar et al., 2004). Also created was a mutant where all four phosphorylation sites contain an aspartic acid (serines 151, 154,155 , and 159).

In order to visualize the location of the wild type and the various phosphomimetic M8 proteins, two polypeptides that are capable of producing a fluorescent signal have been attached to the different $m 8$ constructs. The location of the M8 proteins will be monitored by the visualization of the location of a Yellow Fluorescent Protein (YFP) and a Cyan Fluorescent Protein (CFP) which are attached to the protein of interest within a Drosophila cell line. Use of these molecular reporters within a system requires knowledge of a technique that employs the use of fluorescently labeled molecules. Their properties of excitation at a specific wavelength of light, as well as their emission state which can be viewed at a certain wavelength of light will be used for this project (He et al., 2003). When YFP is excited at a wavelength of $514 \mathrm{~nm}$, it emits a yellow fluorescence which is visible at $527 \mathrm{~nm}$ and when CFP is excited at $434 \mathrm{~nm}$, it emits a cyan fluorescence which is visible at $477 \mathrm{~nm}$ (Patterson et al., 2001). The use of the YFP fluorescence will help visualize the exact location of the mutated M8 proteins, as well as the state of the M8 protein in vivo.

The use of the two fluorescent proteins allows future capabilities of this project the ability to look at fluorescent resonance energy transfer (FRET) between the two fluorescent proteins. FRET occurs when the two fluorescent proteins come into close proximity of each other (5nm), only then will there be energy transfer between the two fluorescent molecules. The creation of 
constructs with two fluorescent proteins attached to the various phosphomimetic variants will allow future studies and the utilization of the energy transfer between the YFP and CFP. Previous studies hypothesize that the non-phosphorylated form of the M8 protein is in a conformation that renders itself autoinhibited (Karandikar et al., 2004). The use of two fluorescently labeled proteins attached to the phosphomimetic variants of M8, along with FRET will give scientists an opportunity to visualize at a cellular level the autoinhibited and uninhibited states of M8 and whether there is a conformational autoinhibition of the protein.

Schneider 2 (S2) cells will be used as a way to express the constructs created using a cotransfection of the constructs into the cell line, which are then grown and used for assaying protein expression. The cell line is commonly referred to as a Drosophila Expression System, or S2 cells (Schneider, 1972). These cells are derived from 20-24 hour old Drosophila embryos and will be used for the visualization of protein expression of the wild type and mutated M8 proteins. These tools will be utilized throughout the duration of the project to help better visualize the cellular localization of M8 phosphorylation.

A Gal4/UAS system will be employed to drive the expression of the various $m 8$ constructs in S2 cells. The Gal4/UAS transcription system was initially discovered in yeast, where the expression of the Gal4 protein serves as a transcriptional activator for the upstream activation sequence (UAS) of a certain target gene. The Gal4 protein binds to the promoter sequence of the UAS activating transcription of the downstream targets of the UAS. This system is used in order to give scientists control over the expression of targeted genes. The use of four differing $m 8$ pUAST constructs allows the upstream activation sequence to be present upstream of the reporter gene. In this case the reporter genes are the differing $C F P-m 8-Y F P$ constructs. 
The reporter gene can only be maximally expressed with the activation of the Gal4 protein. This will occur by using the pMT-Gal4 construct. This construct contains a metallothionein promoter which can be activated by the induction of Copper II Sulfate $\left(\mathrm{CuSO}_{4}\right)$ driving the expression of the Gal4 protein. In theory, when the S2 cells are co-transfected with these two constructs (pMTGal4 and one of the pUAST-CFP- $m 8-Y F P$ constructs) and $\mathrm{CuSO}_{4}$ is added to the cell suspension, the metallothionein promoter will be activated on the pMT-Gal4 and initiate transcription of the Gal4 protein, which will bind to the upstream activation sequence of the $m 8$ constructs and activate transcription of the reporter genes in vivo. This allows for specific control of the activation of the differing constructs. Using this idea of controlling the transfected constructs containing differing fluorescently labeled $m 8$ constructs within the S2 cell; it is the goal of this project is to create a molecular tool using the phosphomimetic $m 8$ constructs. Secondly it is an aim to generate initial data on this inducible system with the hopes of observing the location of these M8 fusion proteins within a Drosophila cell line. 


\section{Materials and Methods \\ Creation of Constructs}

The constructs pET-30a(+)-CFP- $m 8-Y F P$ and pBSII-(KS+)-CFP- $m 8-Y F P$ have been established previously by Dr. Ashok Bidwai and Dr. Clifton Bishop's laboratory. m8S159D primer 1 and primer $2, m 8 S 159 A$ primer 1 and primer 2 and $m 8-19$ forward primer and reverse primers were generously donated by Dr. Ashok Bidwai. The primers that were used for site directed mutagenesis are found in Table 1. These primers align with the sequence of $m 8$, however they contain single or multiple nucleotide substitution(s) (depending on the construct to be created) which convert the serine (S) codon at amino acid number 159 to either alanine (A), aspartic acid (D), or all four serines in the phosphorylation domain to aspartic acids (DDDD). These amino acid substitutions will mimic when the CK2 phosphorylation site in M8 has been phosphorylated or in the "on" state (S to D; $C F P-m 8 S_{159} D-Y F P$ ), when it is unable to be phosphorylated or in the "off" state (S to A; $C F P-m 8 S_{159} A-Y F P$ ), and when all phosphorylation sites mimic being in the fully phosphorylated state (S to DDDD; $C F P-m 8 S D D D D-Y F P$ ). Figure 3 illustrates this process.

Table 1: Site Directed Mutagenesis Primers - Primers used for the site directed mutagenesis (SDM) of the $C F P-m 8-Y F P$ constructs. The underlined nucleotides correspond to the wanted changes in the M8 amino acid sequence.

\begin{tabular}{|c|c|c|}
\hline Name & Sequence & Function \\
\hline$m 8 S 159 \mathrm{~A} P 1$ & CCGGATATCACGCCGACTGCGACAGC & S159A in M8 \\
\hline$m 8 S 159 \mathrm{~A} P 2$ & GCTGTCGCAGTCGGCGTGATATCCGG & S159A in M8 \\
\hline$m 8 S 159 \mathrm{D} P 1$ & CCGGATATCAC $\underline{\text { GACGACTGCGACAGC }}$ & S159D in M8 \\
\hline$m 8 S 159 \mathrm{D} P 2$ & GCTGTCGCAGTGGTCGTGATATCCGG & S159D in M8 \\
\hline$m 8-19 \mathrm{FP}$ & CTCAATGGACAAGGCTCCGCTCGACCCCGCCGACGACGGATATCACGACGACTGCGACAG & D1D2D3D4 in M8 \\
\hline$m 8-19 R P$ & CTGTCGCAGTCGTCGTGATATCCGTCGTCGGCGGGGTCGAGCGGAGCCTTGTCCATTGAG & D1D2D3D4 in M8 \\
\hline
\end{tabular}


The protocols that were used for the site directed mutagenesis of the pET-30a+ constructs were $2 \mu \mathrm{L}$ of the appropriate above $m 8 S_{159} A(0.1 \mathrm{mg} / \mathrm{mL})$ and $m 8 S_{159} D(0.1 \mathrm{mg} / \mathrm{mL})$ forward and reverse primers (Table 1), $5 \mu \mathrm{L}$ of 10X PFU buffer (Stratagene 600153-82), $2 \mu \mathrm{L}$ of pET30a+-CFP-m8-YFP DNA (48 ng/ $\mu \mathrm{L}), 1 \mu \mathrm{L}$ of dNTPs $(40 \mathrm{mM})$ and $37.5 \mu \mathrm{L}$ of de-ionized water per each SDM reaction. To the appropriate tubes $0.5 \mu \mathrm{L}$ PFU DNA polymerase $(2.5 \mathrm{U} / \mu \mathrm{L})$ was added to each mutagenesis reaction and $0.5 \mu \mathrm{L}$ of de-ionized water made up the difference in the control samples. The thermalcylcer protocol that was used is as follows; 1 step of denaturation at $95^{\circ} \mathrm{C}$ for 1 minute, and 16 cycles of: denaturation at $95^{\circ} \mathrm{C}$ for 50 seconds, annealing $50^{\circ} \mathrm{C}$ for 50 seconds and extension at $72^{\circ} \mathrm{C}$ for 8 minutes and one cycle of a 7 minute polishing at $72^{\circ} \mathrm{C}$.

For the pBSII-(KS+)-CFP-m8-YFP template DNA, the protocols were modified slightly due to the difference in the size of the parental vector. The mutagenesis set up that was used contained $1.5 \mu \mathrm{L}$ of $m 8-19(0.1 \mathrm{mg} / \mathrm{mL})$ forward primer and reverse primer found (Table 1) along with $5 \mu \mathrm{L}$ of $10 \mathrm{X}$ PFU buffer (Stratagene $600153-82), 2 \mu \mathrm{L}$ of the pBSII-(KS+)-CFP-m8YFP template DNA $(62.5 \mathrm{ng} / \mu \mathrm{L}), 1 \mu \mathrm{L}$ of dNTPs $(40 \mathrm{mM})$ and $39 \mu \mathrm{L}$ of de-ionized water per each SDM reaction. The appropriate tubes $0.5 \mu \mathrm{L}$ PFU DNA polymerase $(2.5 \mathrm{U} / \mu \mathrm{L})$ was added to each mutagenesis reaction, and $0.5 \mu \mathrm{L}$ of de-ionized water made up the difference in the control samples. The thermalcylcer protocol that was used is as follows; 1 step of denaturation at $95^{\circ} \mathrm{C}$ for 2 minutes, and 20 cycles of: denaturation at $95^{\circ} \mathrm{C}$ for 2 minutes, annealing $65^{\circ} \mathrm{C}$ for 1 minute and extension at $72^{\circ} \mathrm{C}$ for 8 minutes and one cycle of a 6 minute polishing at $72^{\circ} \mathrm{C}$.

After amplification, the constructs were sequenced in order to ensure the proper construct was mutated correctly and contained no irregularities. 


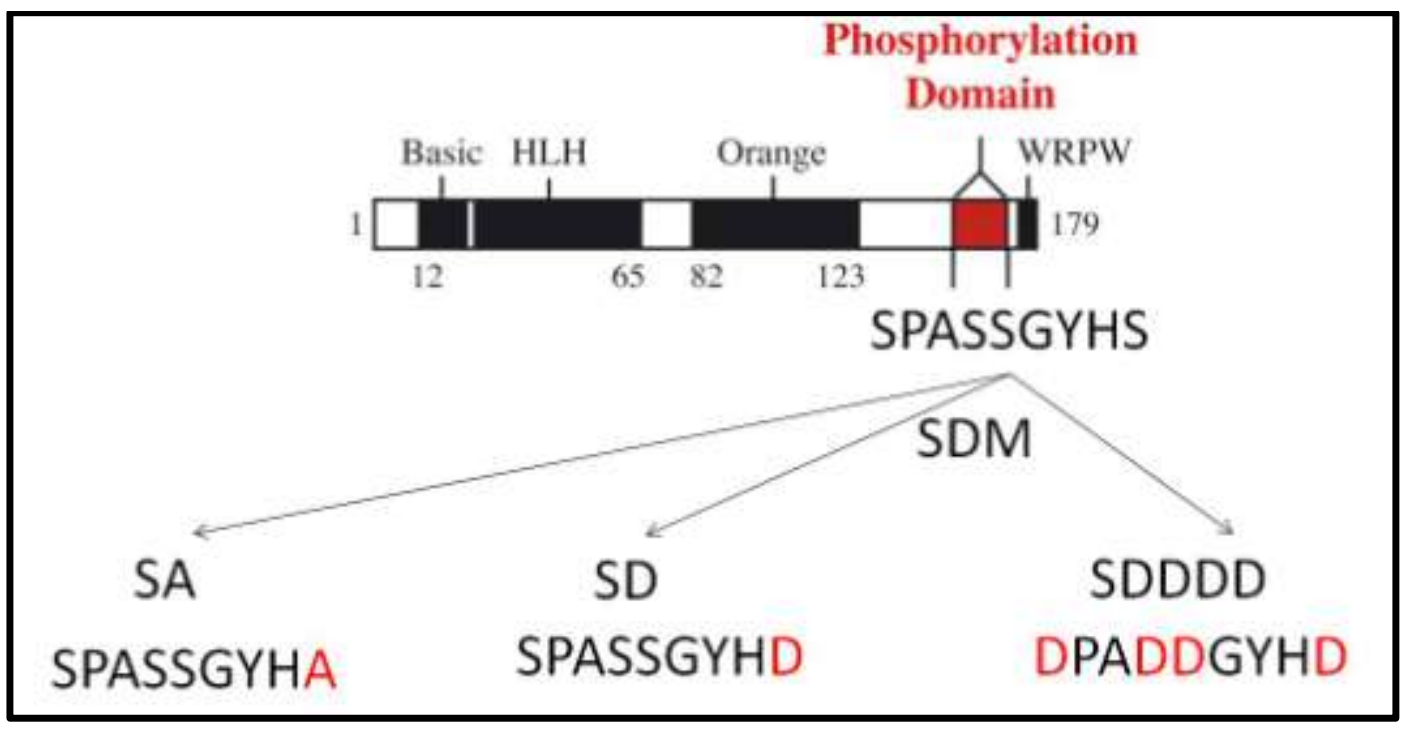

Figure 3: Site Directed Mutated CFP-m8-YFP Constructs- The product of the site directed

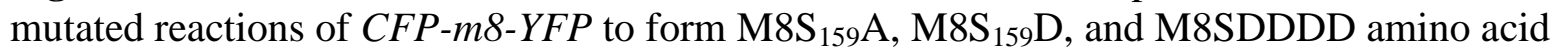
changes within the phosphorylation domain within M8.

\section{Schneider Cell Constructs}

The $C F P-m 8 S_{159} A-Y F P, C F P-m 8 S_{159} D-Y F P, C F P-m 8-Y F P$, and CFP-m8SDDDD-YFP constructs, each in their respective parental vectors (pET-30a+ or pBSII-(KS)) were excised using the EcoRI and NotI restriction endonucleases. These sites flank the fluorescent proteins in the parental vectors and the excised fluorescent $m 8$ inserts were ligated into the pUAST vector in frame. pUAST was cut with EcoRI and NotI respectively allowing ligation of the inserts into the pUAST vector.

The constructs were moved from these vectors into the pUAST vector because the pUAST vector is capable of being expressed in S2 cells and induced by the Gal4 proteins, whereas the pET30a(+) and pBSII-(KS+) vectors are not. The pUAST-CFP-m8S $159 A-Y F P$, pUAST-CFP- $m 8 S_{159} D-Y F P$, pUAST-CFP- $m 8-Y F P$, pUAST-CFP- $m 8 S D D D D-Y F P$ constructs (referred to in the rest of the thesis as $m 8, m 8 S_{159} A, m 8 S_{159} D$, and $m 8 S D D D D$ constructs) were frozen down in glycerol and stored at $-80^{\circ} \mathrm{C}$. These constructs contain an upstream activation 
sequence which can be activated by inducing expression of the Gal4 protein which is in turn produced from activation of the pMT-Gal4 construct (Drosophila Genomics Research Center \#1042). The pMT-Gal4 construct contains a metallothionein promoter linked to a Gal4 gene.

\section{Initiating a S2 Cell Line from a Frozen Sample}

The $\mathrm{S} 2$ cell line arrived frozen in a cryovial with approximately $1 \mathrm{~mL}$ of the $\mathrm{S} 2$ cell line.

The cryovial was thawed slowly by warming it in the palm of one's hand. Two $\mathrm{mL}$ of fresh room temperature Schneider's Drosophila medium (10\% heat inactivated fetal bovine serum, penicillin/streptomycin at $50 \mathrm{U} / \mu \mathrm{L}$ and $50 \mu \mathrm{g} / \mu \mathrm{L}$, and Schneider's Drosophila media) was aliquoted into two $15 \mathrm{~mL}$ conical vials. Once thawed, the cells were split and added to each conical vial containing $2 \mathrm{~mL}$ of Schneider's Drosophila medium. The cells were spun at $65 \mathrm{RCF}$ (x g) for 15 minutes and once spun, the supernatant was aspirated and the cells were resuspended in Schneider's Drosophila medium. The cells were then added to two different $25 \mathrm{~cm}^{2}$ flasks (Corning) containing 5mL of fresh Schneider's Drosophila medium. The cells were allowed to grow at room temperature until a sufficient cell line was established. Growth was monitored over the following days to ensure cells were replicating using an inverted microscope. The cells were passed from one flask to a new one containing Schneider's Drosophila medium every 4-6 days, as their doubling time is approximately 24-48 hours. Passage numbers were recorded each time the cells were passed. Cells began to clump roughly around a cell density of $1-2 \times 10^{6}$ cells $/ \mathrm{mL}$. This clumping did not affect cell growth, and the clumps were broken up when passing cells.

\section{Freezing the S2 Cell Line}

Cells were frozen in order to maintain the cell line in liquid nitrogen using Schneider's Drosophila freezing medium ( $20 \%$ heat inactivated fetal bovine serum, $10 \%$ dimethylsulfate 
(DMSO), penicillin/streptomycin at $50 \mathrm{U} / \mu \mathrm{L}$ and $50 \mu \mathrm{g} / \mu \mathrm{L}$ and Schneider's Drosophila media). The cell suspension was grown to approximately $2,000,000$ cells $/ \mathrm{mL}$ and pelleted by spinning the cells at $180 \mathrm{RCF}(\mathrm{x} \mathrm{g})$. Once pelleted, the supernatant was removed and the cells were resuspended in Schneider's Drosophila freezing medium to bring the concentration to approximately $20,000,000$ cells $/ \mathrm{mL}$. Five hundred $\mu \mathrm{L}$ of the cell suspension was aliquotted into labeled cryovials and allowed to sit at room temperature for 15 minutes. The vials were slowly frozen by placement of the cryovials in a mini cooler at $-80^{\circ} \mathrm{C}$ for $2-3$ days and finally stored in liquid nitrogen for long term storage.

\section{S2 Cell Maintenance}

$\mathrm{S} 2$ cells were maintained in either $25 \mathrm{~cm}^{2}$ cell culture flasks containing a total volume of $5 \mathrm{~mL}$ or a $75 \mathrm{~cm}^{2}$ cell culture flasks containing a total volume of $15 \mathrm{~mL}$. S2 cell cultures were maintained at room temperature with an approximate doubling time of 24-48 hours. Cell densities and cell viability were checked regularly using a hemocytometer and a 1:5 ratio of trypan blue stain to cell culture. Dead cells take up the trypan blue stain while living cells do not take up the stain. Cell counts were taken in order to determine the cell densities of the flasks before passage. Cells were allowed to grow to a density of approximately 10,000,000 cells $/ \mathrm{mL}$ before splitting the culture to a new flask with fresh medium to a density of no less than 500,000 cells $/ \mathrm{mL}$. This resulted in passing cells every 4-6 days.

\section{S2 Cell Growth Curve and Doubling Time}

In order to determine the approximate doubling time and the growth of the S2 cells at differing temperatures, 4 flasks containing approximately $3,000,000$ cells $/ \mathrm{mL}$ were established and maintained at differing temperatures $\left(18^{\circ} \mathrm{C}\right.$, room temperature, $24^{\circ} \mathrm{C}$ and $\left.28^{\circ} \mathrm{C}\right)$. The growth 
temperatures were maintained using fly incubators at $18^{\circ} \mathrm{C}, 24^{\circ} \mathrm{C}$ and $28^{\circ} \mathrm{C}$, along with a room temperature cell line. The room temperature throughout the duration of the study varied between $22^{\circ} \mathrm{C}$ and $24^{\circ} \mathrm{C}$, which corresponded to normal room temperature fluctuations. Cell densities and cell viability were monitored over the course of 180 hours. Four readings from each flask were taken every 11-14 hours and recorded. Using the counting protocols provided with hemocytometer, along with a 1:5 dilution factor based on the use of trypan blue, the appropriate cell counts were plotted to give growth curves and cell viability counts for the varying temperatures (see Figure 8).

\section{S2 Cell Growth Curve and Doubling Time of Transfected and Control Cells}

In order to determine cell viability and doubling time of the S2 cells of transfected cells and control cells, cells were seeded in a $3 \mathrm{~mL}$ petri dish at approximately 800,000 cells $/ \mathrm{mL}$ and maintained at room temperature. Co-transfection protocols for $m 8$ were followed for the transfected cell line as outlined in the protocols below with the exception of the wash stage, as cell counts would be disrupted with washes (see Co-transfection of S2 Cells below). This included transfection of the cells on day two and copper II sulfate induction of cells on day four for the transfected cells only. Cell densities and cell viability were monitored over the course of 146 hours. Four readings from each flask were taken approximately every 11-14 hours and recorded. Using the standards provided with the hemocytometer, along with dilution based on the use of trypan blue, the appropriate cell counts were plotted to give growth curves and cell viability at differing cellular conditions (see Figure 8). 


\section{Determining Rate and Doubling Time for S2 Cells}

Using the equation for cellular growth from Artwell et al., (1999) of $\ln N(t)=\ln N_{0}+r t$ the rate of the number of doublings that occur per hour (r) can be calculated. From this, the doubling rate of the cells $\left(T_{d}\right)$ can be calculated using the equation $T_{d}=\frac{\ln (2)}{r}$. This will give the effective doubling time of the cells over the duration of a given time period and will allow for determination of the physical condition of the cell cultures in differing environments.

\section{Co-Transfection of S2 Cells}

S2 cells were seeded at a density of approximately 800,000 cells $/ \mathrm{mL}$ into a $35 \mathrm{~mm}$ cell culture plate containing of Schneider's Drosophila medium and a total volume of $3 \mathrm{~mL}$. The cells were allowed to grow overnight at room temperature, effectively allowing for a doubling of the cells and for the cells to acclimate to the conditions. For each co-transfection of an $m 8$ construct the following solutions were used: Solution A ( $200 \mu \mathrm{L}$ of $0.25 \mathrm{M} \mathrm{CaCl}_{2}, 10-20 \mathrm{ng}$ of the differing $m 8$ construct DNA, and $1 \mu \mathrm{L}$ pMT-Gal4) and Solution B [200 $\mu \mathrm{L} 2 \mathrm{X}$ HeBS solution $(0.273 \mathrm{M}$ $\mathrm{NaCl}, 0.009 \mathrm{M} \mathrm{KCl}, 0.0025 \mathrm{M} \mathrm{NaHPO}_{4}, 0.011 \mathrm{M}$ Glucose, and 0.0503M HEPES )]. Three negative controls were established using the same procedures that contained both $m 8$ and pMT DNA (which later will have no $\mathrm{CuSO}_{4}$ added to it) (control 1), $m 8$ DNA and $\mathrm{CuSO}_{4}$ (control 2), pMT-Gal4 DNA and $\mathrm{CuSO}_{4}$ (control 3), and a fourth negative control was established that contained cells that contained no transfection solutions or DNA (control 4). Solution A was added drop-wise to Solution B with continual mixing using the vortex and incubated at room temperature for 30-40 minutes, during this step fine white precipitate sometimes becomes visible. This solution was then added drop-wise with swirling to the cells that were seeded in $35 \mathrm{~mm}$ petri dishes. Cells were allowed to incubate at room temperature overnight. The following 
day, cells were pelleted at $23 \mathrm{RCF}(\mathrm{x}$ g) for 15 minutes and allowed to rest 15 minutes then washed with fresh Schneider's Drosophila medium. This washing occurred twice and the cells were re-plated into the same petri dishes supplied with fresh Schneider's Drosophila medium.

Expression was induced on the second day after transfection with the addition of $15 \mu \mathrm{L}$ of $100 \mathrm{mM} \mathrm{CuSO}_{4}$ to the experimental plate containing the $m 8$ construct and pMT-Gal4 construct, the plate containing just the $m 8$ construct (control 2), and the plate with only the pMT-Gal4 construct (control 3). No $\mathrm{CuSO}_{4}$ was added to the plate that contained the $m 8$ construct and pMTGal4 (control 1), or the plate that contained just the cells (control 4). See Table 2 for the cotransfection table of reagents.

Table 2: Co-transfection Table of Reagents-Protocols followed for a single co-transfection of $C F P-m 8-Y F P$ with the appropriate negative controls. The treatment group contained the $C F P$ $m 8$-YFP DNA, pMT-GAL4 and was induced with $\mathrm{CuSO}_{4}$. Control 1 lacked the $\mathrm{CuSO}_{4}$ induction, control 2 lacked the pMT-GAL4 construct, control 3 lacked the CFP-m8-YFP DNA, and control 4 had no transfection reagents added to the system.

\begin{tabular}{|c|c|c|c|c|c|}
\hline Treatment Name & Treatment & Control 1 & Control 2 & Control 3 & Control 4 \\
\hline Solution & $m 8 ;$ pMT-Gal4;CuSO4 & $m 8 ;$ pMT-Gal4 & $m 8 ; C u S O 4$ & pMT-Gal4;CuSO4 & Cells \\
\hline$m 8$ DNA $(10-20 \mathrm{ng} / \mu \mathrm{L})$ & $1 \mu \mathrm{L}$ & $1 \mu \mathrm{L}$ & $1 \mu \mathrm{L}$ & $0 \mu \mathrm{L}$ & $0 \mu \mathrm{L}$ \\
\hline $0.25 \mathrm{M} \mathrm{CaCl} 2$ & $200 \mu \mathrm{L}$ & $200 \mu \mathrm{L}$ & $200 \mu \mathrm{L}$ & $200 \mu \mathrm{L}$ & $0 \mu \mathrm{L}$ \\
\hline pMT-Gal4 $(125 \mathrm{ng} / \mu \mathrm{L})$ & $1 \mu \mathrm{L}$ & $1 \mu \mathrm{L}$ & $0 \mu \mathrm{L}$ & $1 \mu \mathrm{L}$ & $0 \mu \mathrm{L}$ \\
\hline $\mathrm{CuSO} 4(100 \mathrm{mM})$ & $15 \mu \mathrm{L}$ & $0 \mu \mathrm{L}$ & $15 \mu \mathrm{L}$ & $15 \mu \mathrm{L}$ & $0 \mu \mathrm{L}$ \\
\hline
\end{tabular}

\section{Observation of Activity of Constructs within the Cells by Confocal Microscopy}

Experimental and control cells were observed on days one and two after induction with $100 \mathrm{mM} \mathrm{CuSO}_{4}$ using the Olympus FV1000 confocal microscope. Ten $\mu \mathrm{L}$ of cell suspension was added to a slide with a cover slip and viewed using the Olympus FV 1000. Once the slide was prepared, a drop of immersion oil (Olympus) was added to the cover slip and the stage was lowered using the "focus" buttons located on the side of the microscope. The slide was set in the 
proper place and cells were located using white light and the 20X OIL lens. The cells were brought into focus and healthy looking cells were found using the white light. At this point the 60X OIL lens was brought into the correct positioning and the $515 \mathrm{~nm}$ (EYFP) dye and laser was set up for excitation at $515 \mathrm{~nm}$ and viewing the emission of YFP at $530 \mathrm{~nm}$ and higher. The intensity of the laser was set to $9 \%$, with HV (sensitivity of detector adjustment) at 650 volts, $2 \mathrm{X}$ gain and 10\% offset. Also the TD1 (Transmitted light Detector) channel was used to capture the white light image of the cell in order to determine the cellular components of the cells. This setting varied with a HV of around 110-190 volts and a 1X gain. Once established, an XY repeat was initiated and the depth of the cell was determined using the hand focus to determine where the topmost and bottommost layer of the cell was. Once found, these depths were saved as the uppermost and bottommost cell depths and a Z stack was performed on the cell with pictures being taken every $0.50 \mu \mathrm{m}$. Once this was completed the image was saved in the .oib and .oif formats to an external hard drive for data analysis. No two areas of the same slide would be crossed, to ensure that a cell was not photographed twice. This was done using a scanning motion that scanned across the slide and then moved down to look for healthy cells.

\section{Co-Transfection Data Collection and Analysis}

Z-stack images were captured for each individual transfection $\left(m 8, m 8 S_{159} A, m 8 S_{159} D\right.$, $m 8 S D D D D$ ) which contained treatment cells and the four different controls (control 1, control 2, control 3, control 4). Once saved, individual images were viewed to determine the location of the nucleus relative to the z-position within the cell. A region of interest $\left(\mathrm{ROI}_{\text {total }}\right)$ was created around the cell in the specific z-position(s) where the nucleus was visible (measured in $\mu \mathrm{m}^{2}$ ). In this region of interest, the average intensity of fluorescence for the three specific z-positions was recorded, these values were averaged to give one mean intensity of fluorescence value 
throughout the three differing $\mathrm{z}$-positions $\left(\mathrm{MIF}_{\text {total }}=\operatorname{avg} \mathrm{F}_{\mathrm{z} \text {-pos } 1}+\operatorname{avg} \mathrm{F}_{\mathrm{z} \text {-pos } 2}+\ldots+\operatorname{avg} \mathrm{F}_{\mathrm{z} \text {-pos } 3} / 3\right)$. The size of the region of interest remained the same throughout the z-positions and was also recorded $\left(\mathrm{ROI}_{\text {area }}\right)$. This was used in order to gather an overall average intensity of fluorescence per micron ${ }^{2}$ and recorded as "Signal" $\left(\right.$ Signal $\left._{\text {total }}=\mathrm{MIF}_{\text {total }} / \mathrm{ROI}_{\text {total }}\right)$. This exact procedure was followed using an area within the same picture and z-stack positions that did not contain any cell and recorded as "Noise" (Noise $=\mathrm{MIF}_{\text {Noise }} / \mathrm{ROI}_{\text {Noise }}$ ). This served as an internal control to determine the background noise within the different frames. This value was subtracted from the signal within the cell in order to give a true value for the average intensity/micron ${ }^{2}$ (fluorescence) of the cell at the nuclear $\mathrm{z}$-stack positioning (Fluorescence total $=$ Signal $_{\text {total }}-$ Noise $)$.

Once the fluorescence data were gathered for all four controls and the treatment group, it was determined that cells that were not transfected should be removed from the data. This was decided because if not removed, then the data could potentially be biased by non-transfected cells and thus dilute the true fluorescent signals. Control cells at the time of the transfection assay were used to determine threshold values in each transfection experiment. The specific cells

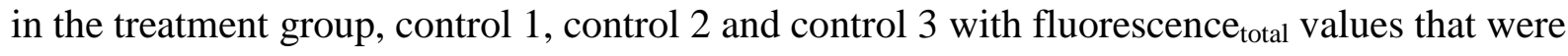
greater than the overall average fluorescence ${ }_{\text {total }}$ of the control 4 cells were chosen for analysis. See Figures 4 and 5 for how data analysis were performed. 


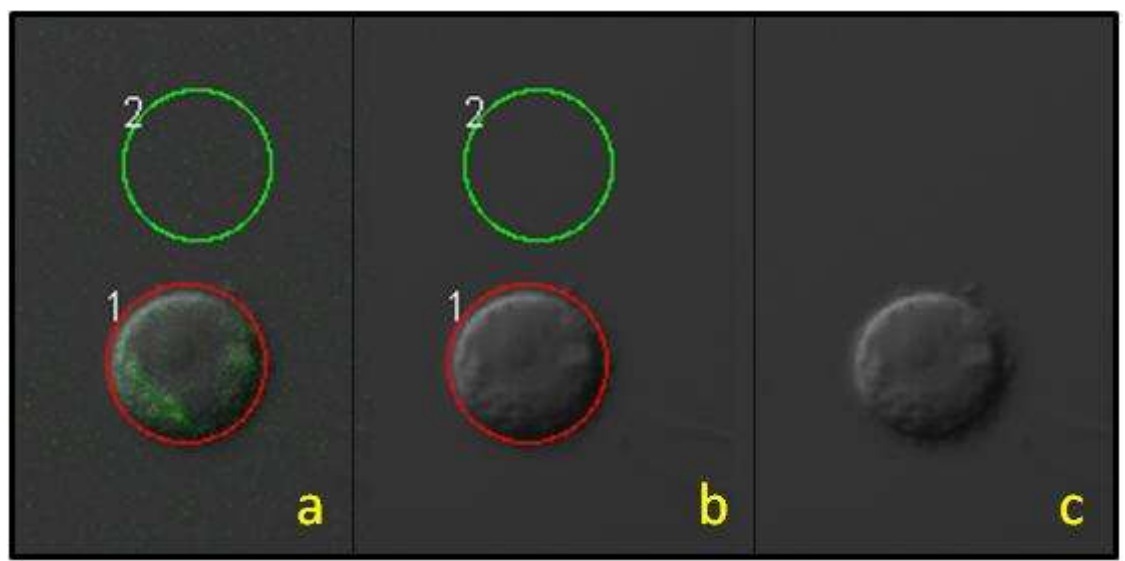

Figure 4: Data Collection of Mean Intensity of Fluorescence in One Z-Position - Above displays one z-position within the cell. Frame a displays the noise (area 2) and signal (area 1) region of interests with the fluorescence displayed. Frame $b$ indicates the regions of interest with no fluorescence being shown. Frame c shows the cell with no regions of interest or fluorescence.

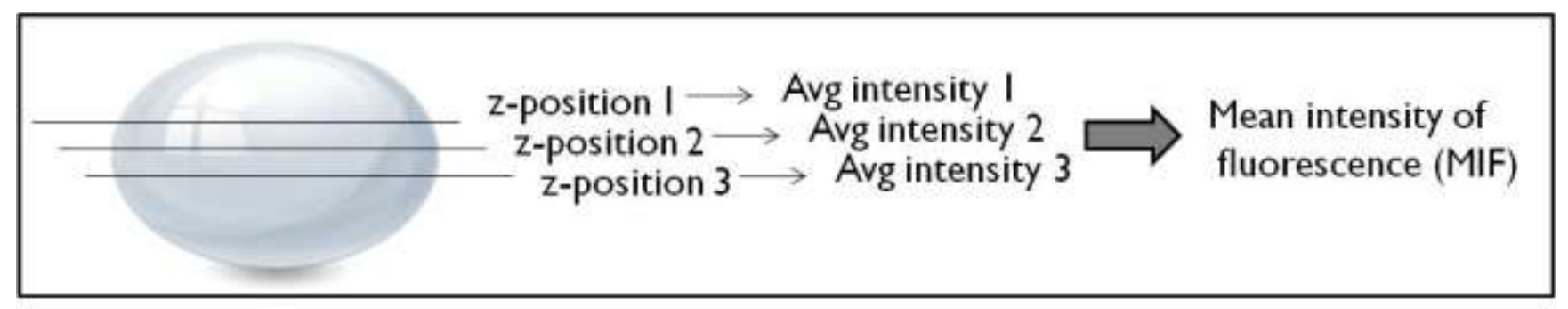

Figure 5: Data Collection of Mean Intensity of Fluorescence - Cells (represented by the white oval) were found where the nucleus was visible. At these positions the average intensities were recorded at the differing z-positions and averaged to give the mean intensity of fluorescence (MIF) for the region of interest (ROI) in question.

\section{Co-Transfection Statistical Analysis}

A one-way ANOVA test was performed on the data collected with the Tukey-Kramer HSD multiple comparison procedure on the Signal-Noise data collected for each transfection $\left(m 8, m 8 S_{159} A, m 8 S_{159} D, m 8 S D D D D\right)$. This analysis was run to determine if there were statistical

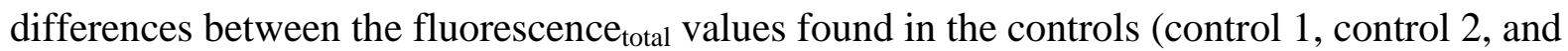
control 3) versus the treatment group for all the constructs. Control 4 was removed from the data analysis portion, as cells within each group were already selected for based on their 
fluorescence $_{\text {total }}$ value that fell above the control 4 average value. The level of significance that the data were tested against was $\alpha=0.05$. In ANOVA results, this value indicates a $95 \%$ confidence that differences between groups do or do not exist.

\section{Determining Localization of M8, $M 8 S_{159} A, M 8 S_{159} D$, and $M 8 S D D D D$}

Mean intensity of fluorescence $\left(\mathrm{MIF}_{\text {total }}\right)$ data from the above study were also used to determine whether there was a difference in the localization of the different fusion proteins (M8,

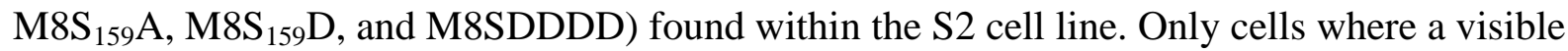
nucleus could be defined were used, if a nucleus was not apparent, then the treatment cell was not used for this study. Once the appropriate cells were chosen, a nuclear region of interest was established around the nuclear membrane based on visual determination of the border of the nucleus under white light microscopy. The z-stack positions that were used to collect the previous studies data, were used to collect the mean intensity of fluorescence $\left(\mathrm{MIF}_{\text {nuc }}\right)$ found within the nucleus. Finally the nuclear value of mean intensity of fluorescence was subtracted out from the total cell fluorescence to give the cytoplasmic fluorescence of each cell $\left(\mathrm{MIF}_{\text {total }^{-}}\right.$ $\left.\mathrm{MIF}_{\text {nucl }}=\mathrm{MIF}_{\text {Cyto }}\right)$. These are representative values of the cytoplasmic fluorescence $\left(\mathrm{MIF}_{\text {cyto }}\right)$ of

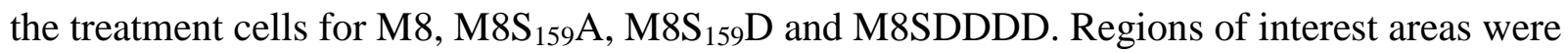
not taken into consideration for this study as each cell was compared back to the original cell. The mean intensity of fluorescence was solely based on the intensity of fluorescence within the nucleus and total individual cell and not between other sized cells. Therefore, the size was not a factor in these data. 


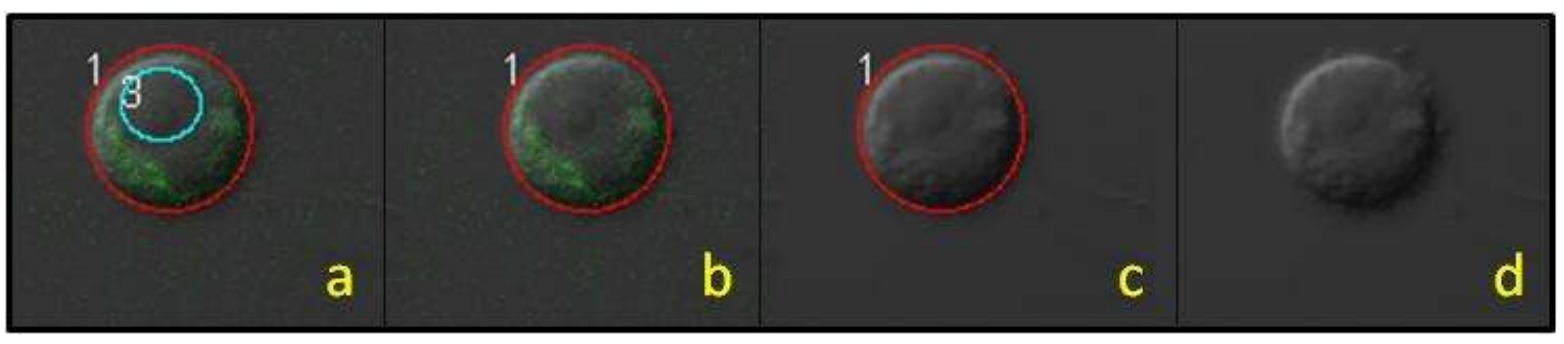

Figure 6: Data Collection of Intensity of Fluorescence in One Z-Position for the Nucleus and Total Cell - Above frames show one z-position for a single cell. Frame a displays the nuclear region of interest (area 3) and total region of interest (area 1) with YFP fluorescence. Frame $\mathrm{b}$ indicates only the total region of interest (area 1). Frame $\mathrm{c}$ shows the total region of interest (area 1) with no YFP fluorescence. A visible nucleus can be observed. Finally frame d displays the cell with no YFP fluorescence or regions of interest.

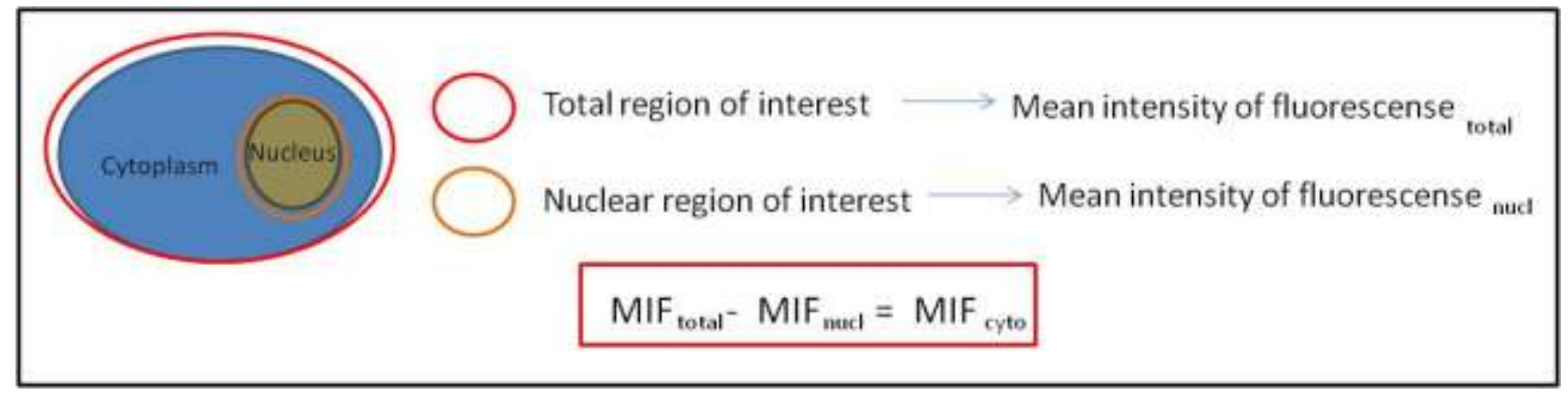

Figure 7: Mean Intensity of Fluorescence Data Collection - Data collected for one z-position within the cell. Total region of interest surrounded the cell and the nuclear region of interest surrounded the nucleus. Average intensity for this position was taken and averaged with the other z-positions. Then the nuclear intensity was subtracted from the total intensity to give the cytoplasmic intensity of fluorescence.

\section{Statistical Analysis of Comparing the Cytoplasmic Fluorescence of M8, M8S ${ }_{159} A$, $M_{8 S_{159} D \text {, and } M 8 S D D D D}$}

A positive value of $\mathrm{MIF}_{\text {cyto }}$ indicated that there was a higher average fluorescence value in the cytoplasm when compared to the value of fluorescence in the nucleus (based on determination of the nuclear location using white light microscopy). Thus, that cell was counted as a cytoplasmic location for the specific protein of interest. However if the $\mathrm{MIF}_{\text {cyto }}$ was a negative number, then it indicated that the mean intensity of fluorescence was higher within the nucleus than the entire cell, and thus was counted as a nuclear location of the specific protein 
within the cell for the specific construct. From these values, it was possible to determine whether the mean intensity of the fluorescence value was greater coming from the nucleus or the cytoplasm (Table 3). 


\section{Results \\ Creation of the Phosphomimetic $m 8$ Variants}

Three phosphomimetic variants of $m 8$ were engineered with wild type $m 8$ flanked by $C F P$ and $Y F P(C F P-m 8-Y F P)$. Subsequent site-directed mutagenesis reactions were initiated using primers that contained single or four codon-level substitutions at key phosphorylation positions within the phosphorylation domain of M8. These mutagenesis reactions thus yielded fluorescently labeled constructs that mimicked M8 in its wild type state, with the CK2 phosphorylation site serine replaced by an alanine, or aspartic acid, and with all four phosphorylation sites replaced by aspartic acids. Sequence analysis of these constructs demonstrated successful codon changes and that the constructs remained in frame for correct translation.

\section{Environmental Effects on Growth and Viability}

Results of two experiments determined the effect of differing temperatures and environments (transfected/control) on cellular proliferation and viability. The first of these experiments investigated different temperatures for growth conditions of non-transfected S2 cells. A secondary experiment was set up to observe the effect of transfection on growth rate. As indicated by Figure 8, the data demonstrates the cellular growth curves for cells over a range of 180 hours for the temperature study, and over 146 hours for the transfection study. At all four temperatures, there is an increase in cellular densities over time but with differing rates, and the transfected cells have very little to no cellular growth when compared to the control cells at room temperature. 


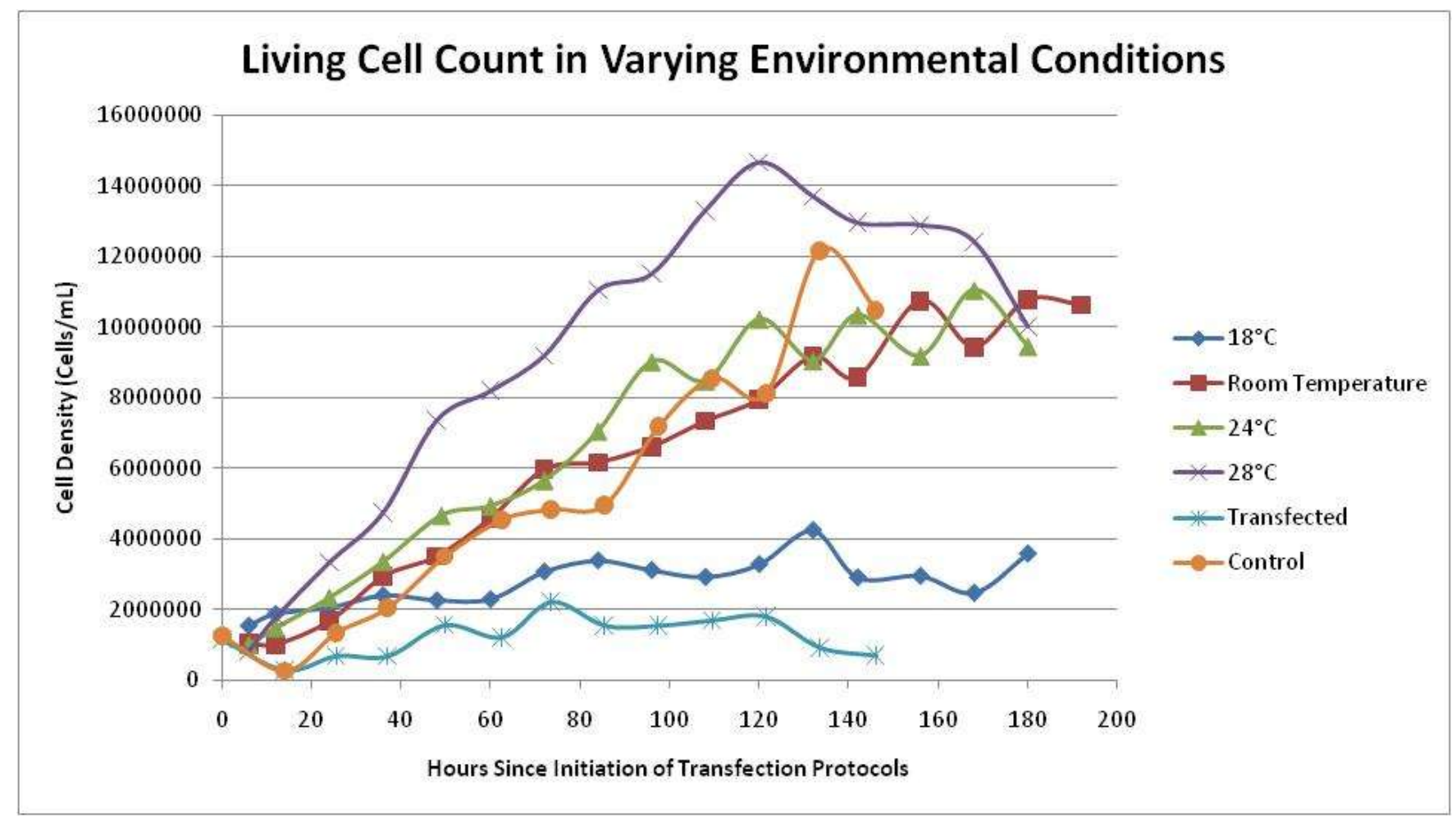

Figure 8: Cellular Growth Curves for Differing Environmental Conditions - Compiled data for two different studies (temperature and transfection). The temperature study ranged over 180 hours and included the cells maintained at $18^{\circ} \mathrm{C}$, room temperature $\left(\sim 22^{\circ} \mathrm{C}\right), 24^{\circ} \mathrm{C}$, and $28^{\circ} \mathrm{C}$. The second study observed the transfected cells and control cells (both at room temperature), light blue and gold lines respectfully, over a period of 146 hours.

As indicated in Figure 8, the cells that were maintained at $18^{\circ} \mathrm{C}$ had a very slow rate of growth as indicated by the calculated relative growth rate according to Artwell et al. (1999). The doubling time for these cells was 143.28 hours (Artwell et al., 1999). Also indicated from Figure 9, the viability of the S2 cells at this temperature was the lowest of the four temperatures with around $60 \%$ viability.

Cells maintained at room temperature, $24^{\circ} \mathrm{C}$ and the control cells from the transfection study mimicked one another with doubling rate, doubling time and cellular viability. The growth curves in Figure 8 are almost identical, indicating comparable rates of growth. doubling time for room temperature, $24^{\circ} \mathrm{C}$, and control cells was 56.06 hours, 53.81 hours and 47.762 hours 
respectively. When examining the cells maintained at these temperatures, Figure 9 indicates a cellular viability for these environments fluctuating around $80 \%$ over the duration of the experiments.

Cells that were maintained at $28^{\circ} \mathrm{C}$ (Figure 8) demonstrated a growth curve with a plateau after approximately 120 hours. Using the data as a whole over the 180 hour time span, the doubling rate for these cells was 48.65 hours; however if you remove the data points after 120 hours, the data is more representative of the most relevant rate of growth for these cells. When excluding the measurements made after 120 hours the relevant doubling rate for the cells is 27.63 hours. The cell viability at $28^{\circ} \mathrm{C}$ is calculated at $80 \%$ until the plateau at 120 hours, and after this time point the viability of the cells decreased rapidly to around $50 \%$.

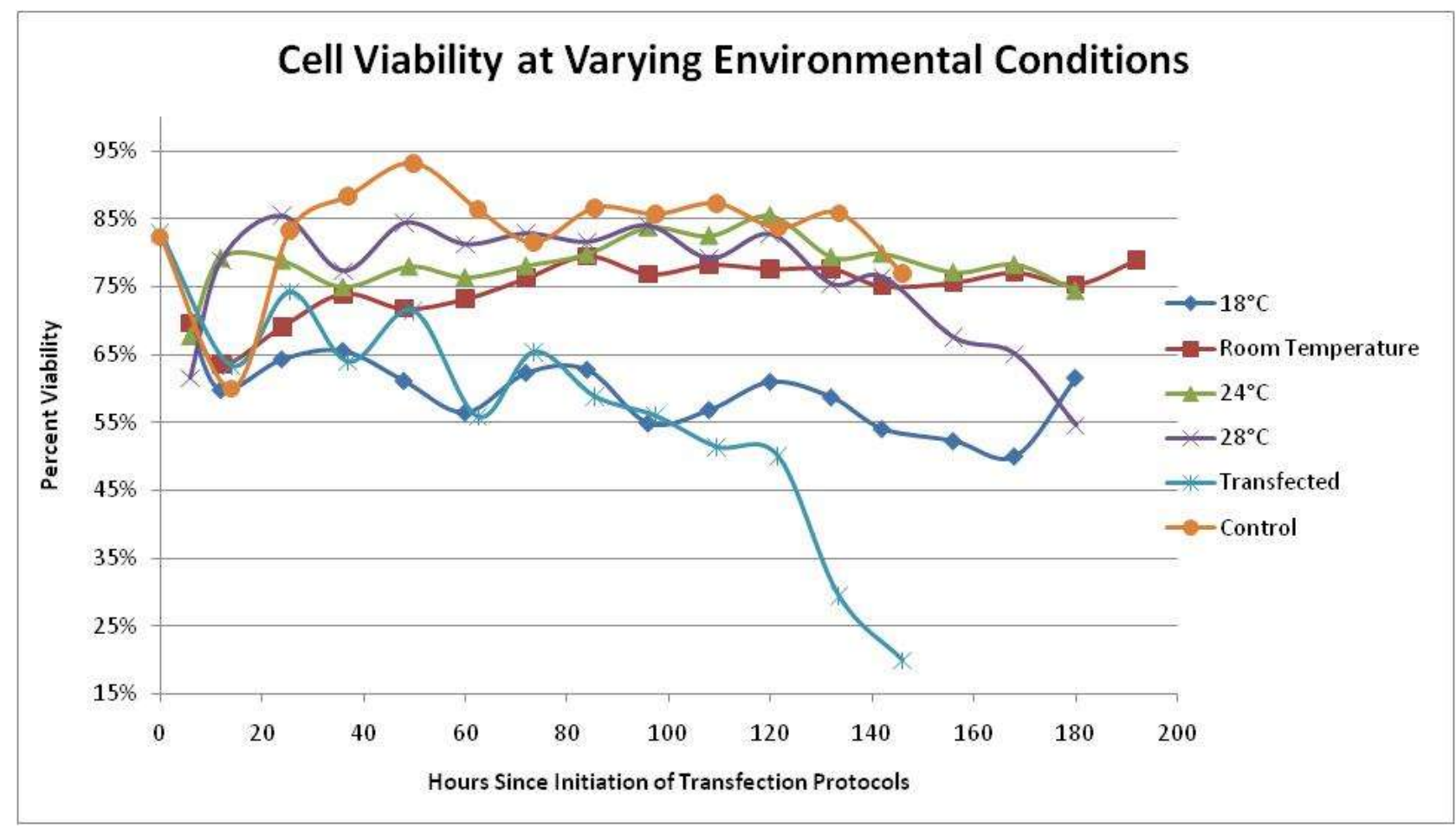

Figure 9: Cell Viability At Differing Environmental Conditions - Cell viabilities were calculated using the total cell count and living cell counts based on staining using Trypan Blue. All temperatures and treatments except for $18^{\circ} \mathrm{C}$ and the transfected cells maintained viability around $80 \%$. 
A second experiment demonstrated that the cell viability was affected by transfection. As indicated by Figure 8, the transfected cells had a negative trend when looking at the rate of growth. This demonstrates a sizeable amount of cell death. Also visible in Figure 9 is the difference in cell viability between the transfected and control cell lines. The control cells maintained a viability of around $80 \%$ whereas the transfected cells continually decline from $80 \%$ to $20 \%$ over the course of 146 hours.

\section{Preliminary Data on the Effects of Co-Transfection of $m 8, m 8 S_{159} A, m 8 S_{159} D$ and m8SDDDD Using S2 Cells}

Initial data was generated on the effectiveness of the co-transfection. When observing the fluorescence in the co-transfected S2 cells with one of the various treatments $\left(m 8, m 8 S_{159} A\right.$, $m 8 S_{159} D$, and $m 8 S D D D D$ ) versus the control cells, several observations can be made. ANOVA of the data indicated that there is a significant difference between the fluorescence values of the

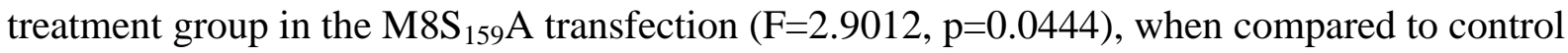
three. This is indicated by the letters above the bars in the graphs in Figure 10. The letters indicate significance between the groups. If bars have the same letter above them, for instance, A and $\mathrm{AB}$ (both containing $\mathrm{A}$ ) then there is no significant difference between those two groupings. $\mathrm{AB}$ would also have no significant difference between any other groping that contained B. However, groups with dissimilar letterings such as A and B, have a statistical difference between those two groupings. When observing the statistical difference between the other transfections, no statistical differences between the treatment groups and the controls is apparent when looking at $\mathrm{M} 8(\mathrm{~F}=0.2650, \mathrm{p}=0.8504), \mathrm{M} \mathrm{S}_{159} \mathrm{D}(\mathrm{F}=2.3563, \mathrm{p}=0.0796)$ and $\mathrm{M} 8 \mathrm{SDDDD}(\mathrm{F}=2.3464$, $\mathrm{p}=0.0854)$. There is no statistical difference between any of the groups within these tranfections 
(Tukey-Kramer HSD). See figures below for the graphs corresponding to the different cotransfection fluorescence data collected (Figures 10-13).

Observing all four transfections on one graph (Figure 14), some key trends can be observed. Initially the first trend that is apparent for control 3 is that (pMT-Gal4, $\mathrm{CuSO}_{4}$ ) fluorescence values are uniform across all the transfections. The fluorescence value for this control ranges from 0.4-0.5 intensity/micron ${ }^{2}$ and varied very little across each transfection. There were higher levels of fluorescence in controls 1 and 2 along with the treatment groups when compared to control 3. However, only in $\mathrm{M} 8 \mathrm{~S}_{159} \mathrm{~A}$ is there a statistical difference. These trends observed in Figure 14 serve as preliminary data, which are easier observed as a complete dataset and will be explored in the discussion of this thesis. 


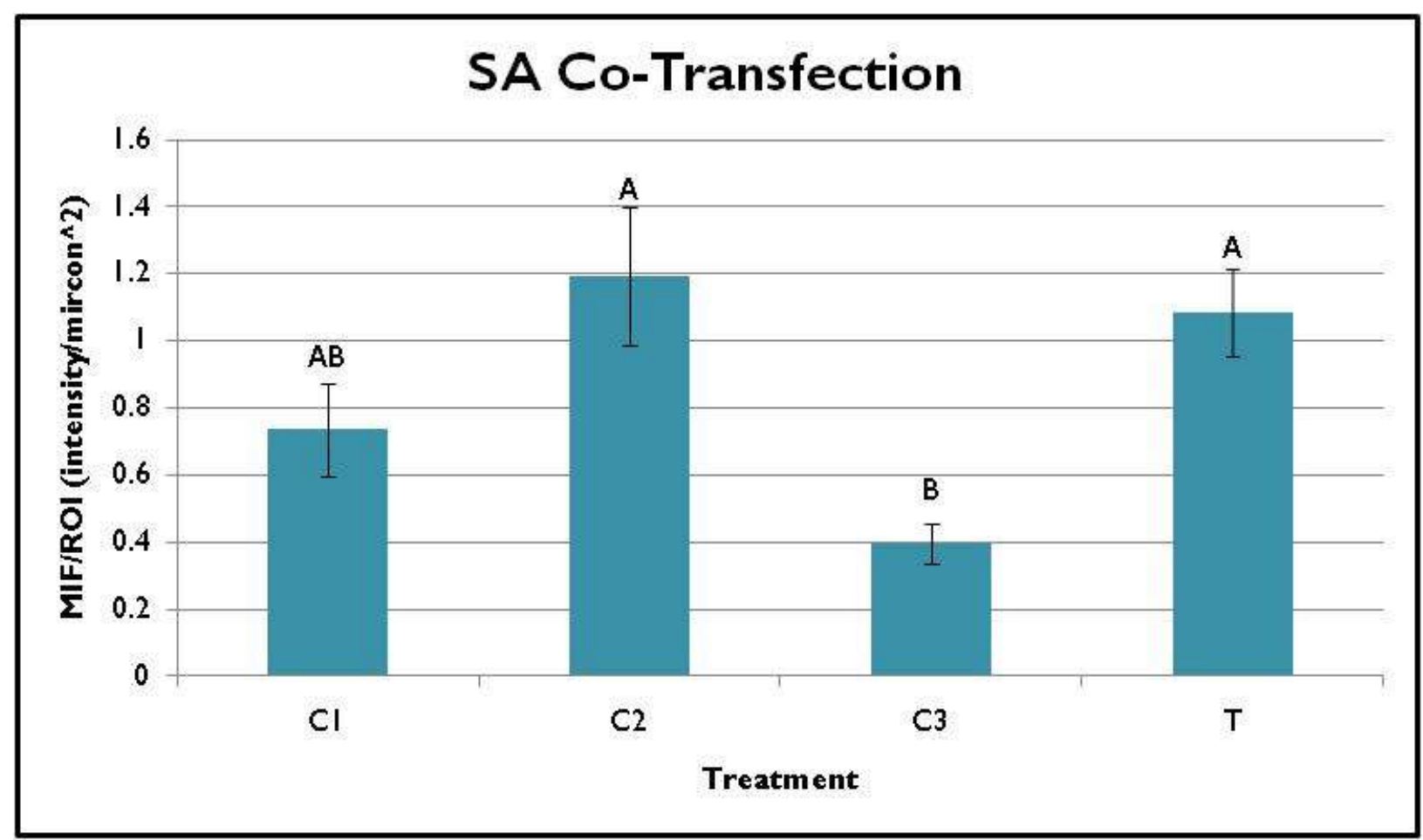

Figure 10: $C F P-m 8 S_{159} A-Y F P$ Co-transfection Fluorescence Values - Data from the CFP$m 8 S_{159} A-Y F P$ transfection of the treatment $(\mathrm{T})$ and control 1-3 $(\mathrm{C} 1, \mathrm{C} 2, \mathrm{C} 3)$. The treatment group contained the $C F P-m 8 S_{159} A-Y F P$ construct, pMT-GAL4, and $\mathrm{CuSO}_{4}$. Control one did not have a $\mathrm{CuSO}_{4}$ induction, control two did not contain pMT-GAL4, and control three did not contain $C F P-m 8 S_{159} A-Y F P$. Statistical analysis indicates a statistical difference between the treatment group and control three, but not control one or two $(\mathrm{F}=2.9012, \mathrm{p}=.0444)$. 


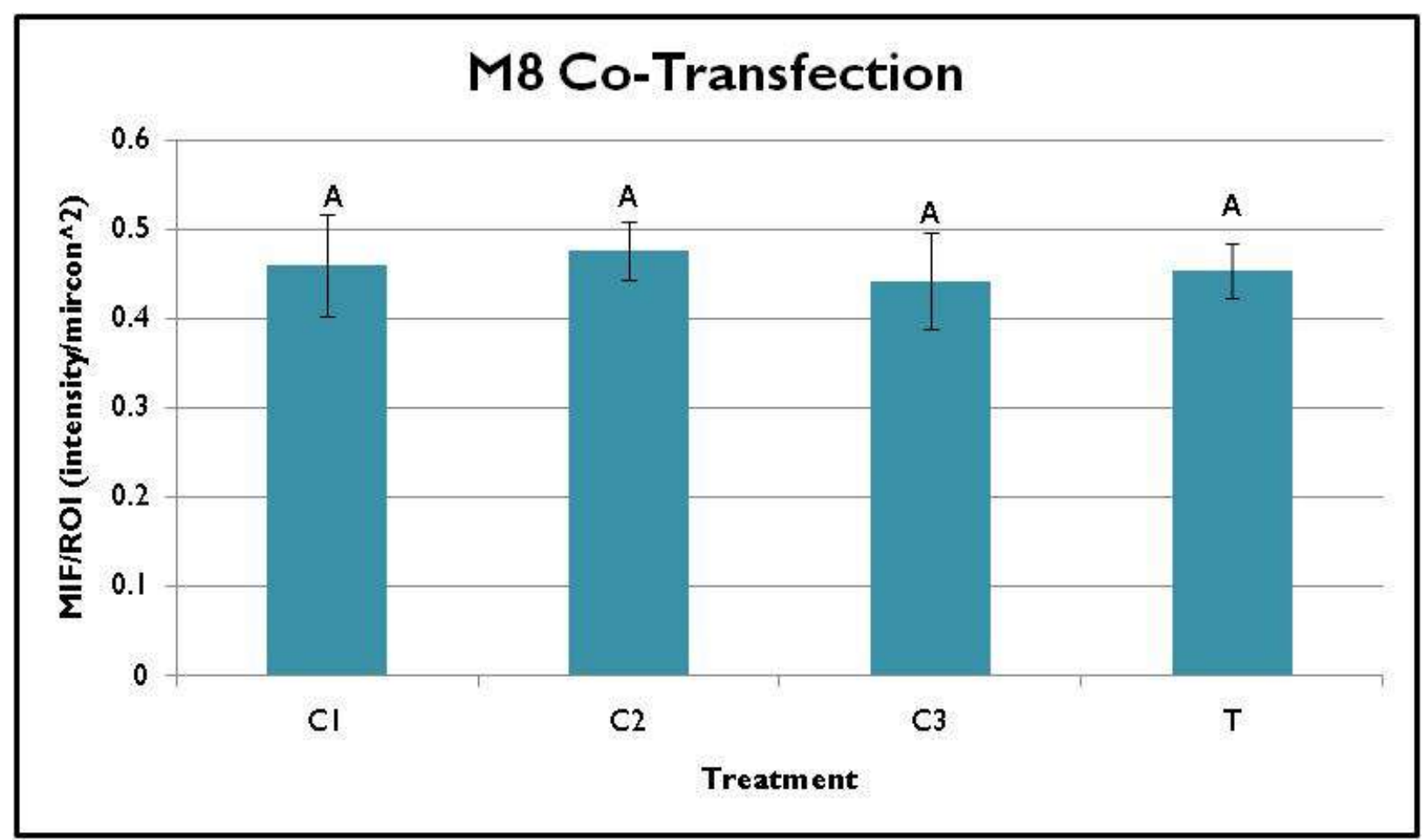

Figure 11: CFP-m8-YFP Co-transfection Fluorescence Values - Data from the $C F P-m 8-Y F P$ transfection of the treatment $(\mathrm{T})$ and control 1-3 $(\mathrm{C} 1, \mathrm{C} 2, \mathrm{C} 3)$. The treatment group contained the $C F P-m 8-Y F P$ construct, pMT-GAL4, and $\mathrm{CuSO}_{4}$. Control one did not have a $\mathrm{CuSO}_{4}$ induction, control two did not contain pMT-GAL4, and control three did not contain CFP-m8-YFP.

Statistical analysis indicates no statistical difference between the treatment and the three controls $(\mathrm{F}=0.2650, \mathrm{p}=0.8504)$. 


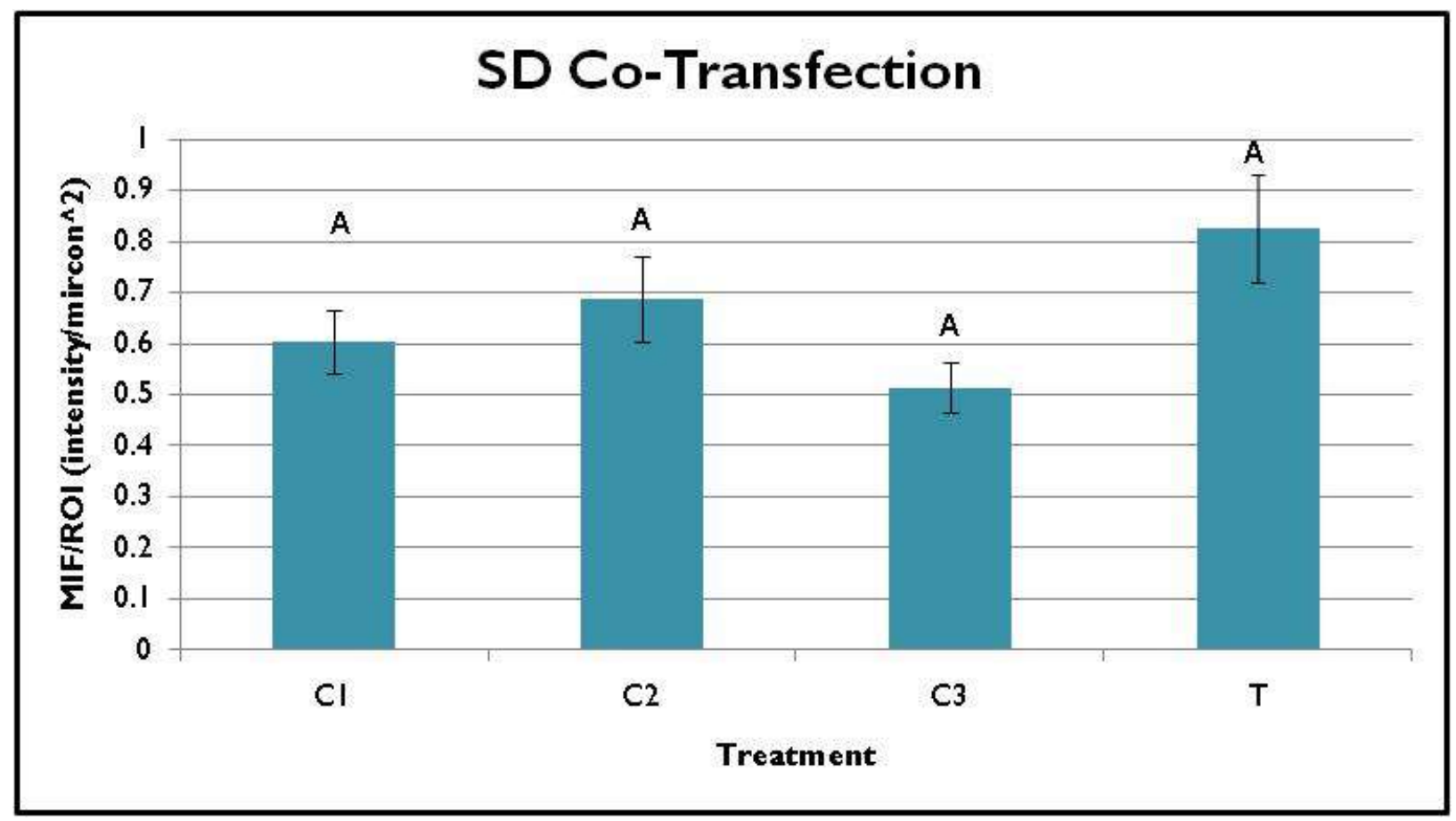

Figure 12: $C F P-m 8 S_{15} D$-YFP Co-transfection Fluorescence Values - Data from the $C F P$ $m 8 S_{159} D-Y F P$ transfection of the treatment $(\mathrm{T})$ and control 1-3 $(\mathrm{C} 1, \mathrm{C} 2, \mathrm{C} 3)$. The treatment group contained the $C F P-m 8 S_{159} D-Y F P$ construct, pMT-GAL4, and $\mathrm{CuSO}_{4}$. Control one did not have a $\mathrm{CuSO}_{4}$ induction, control two did not contain pMT-GAL4, and control three did not contain $C F P-m 8 S_{159} D-Y F P$. Statistical analysis indicates no statistical difference between the treatment and the three controls $(\mathrm{F}=2.3563, \mathrm{p}=.0796)$. 


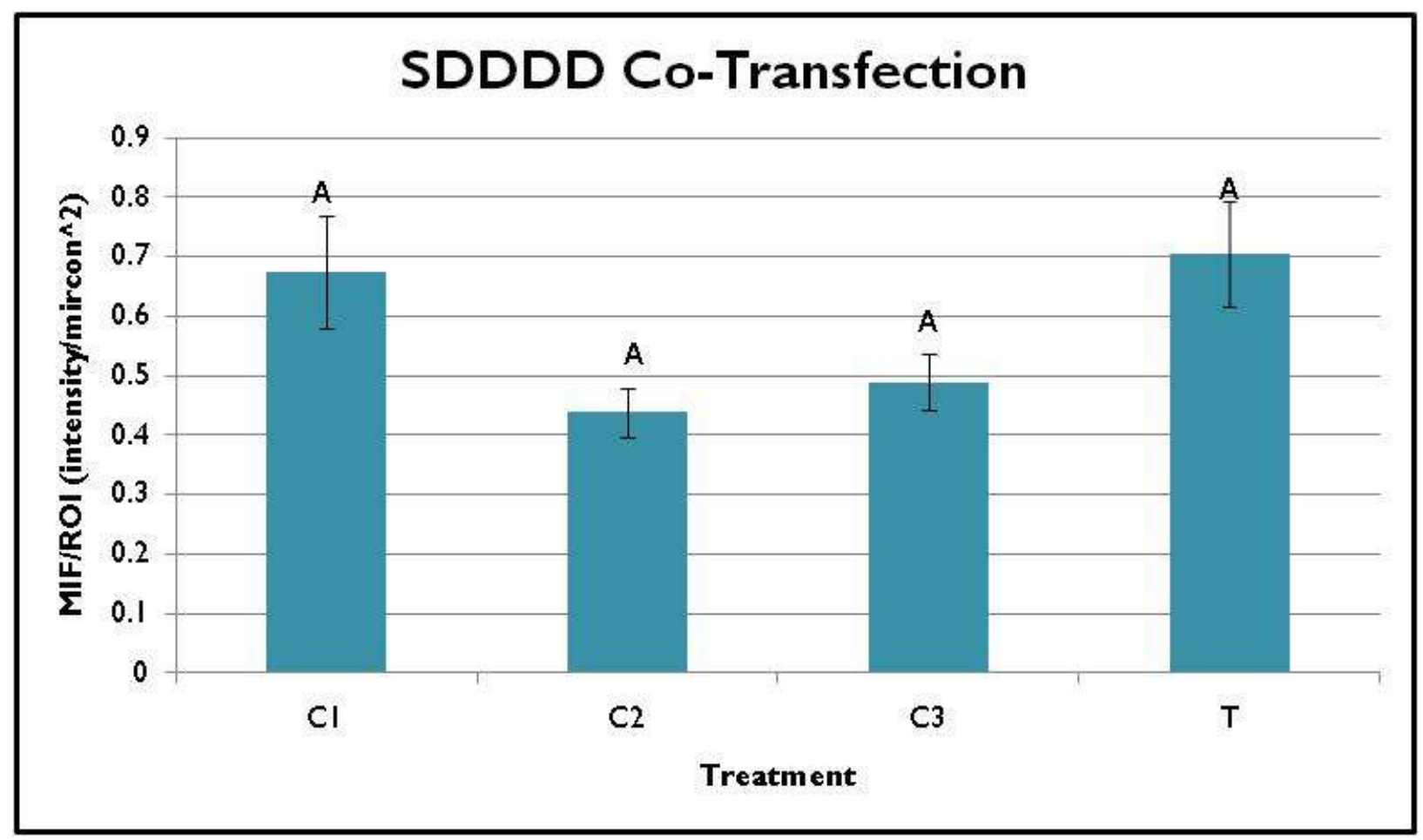

Figure 13: CFP-m8SDDDD-YFP Co-transfection Fluorescence Values - Data from the $C F P$ $m 8 S D D D D-Y F P$ transfection of the treatment $(\mathrm{T})$ and control 1-3 $(\mathrm{C} 1, \mathrm{C} 2, \mathrm{C} 3)$. The treatment group contained the CFP-m8SDDDD-YFP construct, pMT-GAL4, and $\mathrm{CuSO}_{4}$. Control one did not have a $\mathrm{CuSO}_{4}$ induction, control two did not contain pMT-GAL4, and control three did not contain $C F P-m 8 S D D D D-Y F P$. Statistical analysis indicates no statistical difference between the treatment and the three controls $(\mathrm{F}=2.3464, \mathrm{p}=.0854)$. 


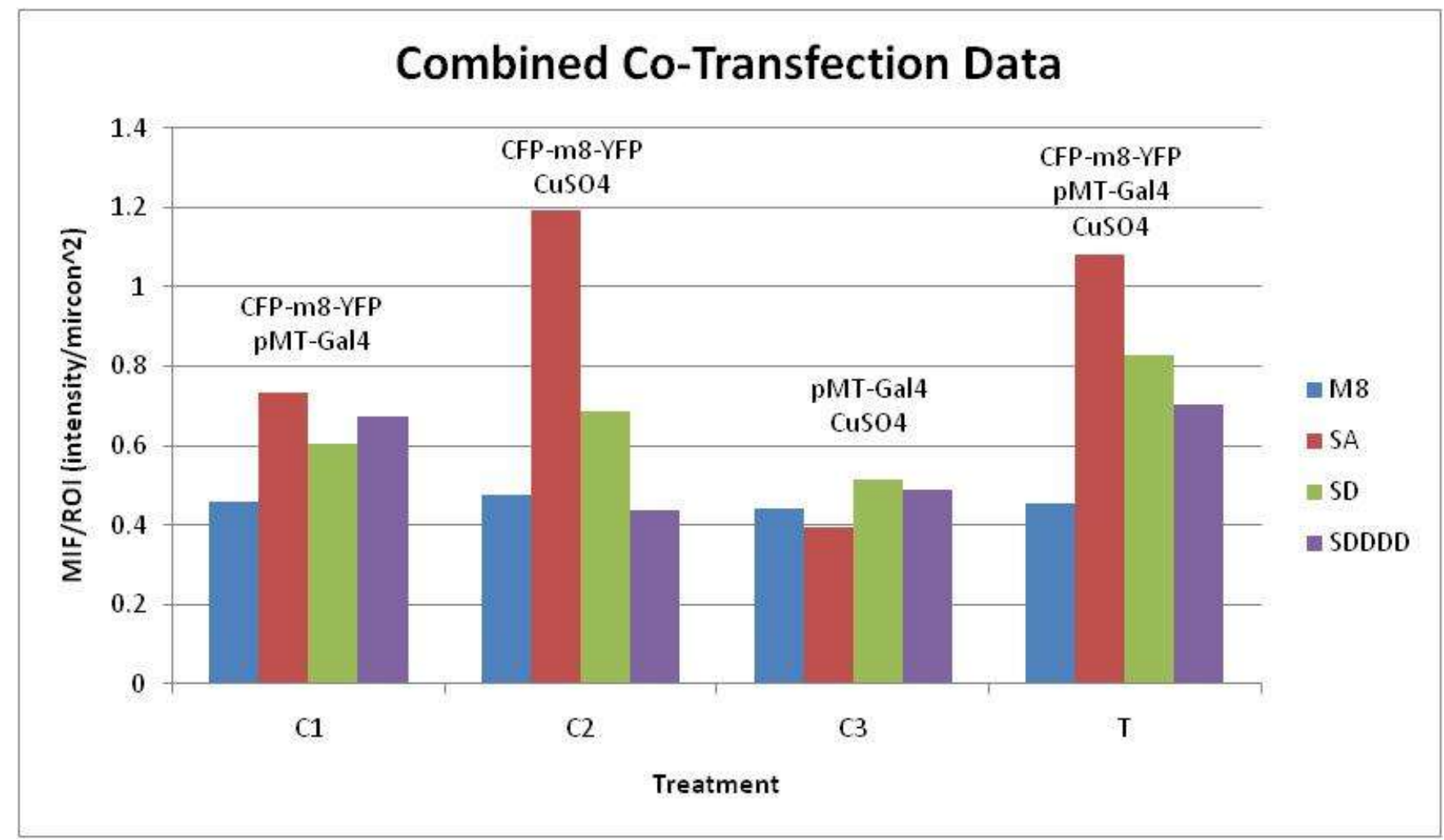

Figure 14: Combined Co-transfection Data - Fluorescence data for all four $m 8, m 8 S_{159} A$, $m 8 S_{159} D$, and $m 8 S D D D D$ transfections. Control 3, containing no fluorescent protein had the least amount of fluorescence (0.4-0.5 intensity/micron ${ }^{2}$ ) while control and treatment groups that contained a fluorescent protein contained a higher value of fluorescence with the exception of $m 8$.

\section{Cellular Location of $M 8, M 8 S_{159} A, M 8 S_{159} D$ and $M 8 S D D D D$ in $S 2$ Cells}

Data collected for the localization study of the differing constructs indicated that cells with positive $\mathrm{MIF}_{\text {cyto }}$ values had the preponderance of fluorescence in the cytoplasm. Cells with a negative $\mathrm{MIF}_{\text {cyto }}$ demonstrated a stronger fluorescence value located in the nucleus for the given constructs. Table 3 displays the cellular localization of the different constructs based on the predominance of fluorescence within the treatment cells. As indicated by Table 3 and the research performed in this experiment with only a white light reference for the nucleus, all four fusion proteins had a higher value of fluorescence located in the cytoplasm, while M8 and M8SA 
displayed two cells each with a nuclear fluorescence value which was greater than the cytoplasmic fluorescence.

Table 3: Localization Study of M8, M8SA, M8SD and M8SDDDD - Table presents the localization counts based off of the cytoplasmic mean intensity of fluorescence $\left(\mathrm{MIF}_{\text {cyto }}\right)$. Positive values indicate a higher value of fluorescence in the cytoplasm and negative values indicate a higher value of fluorescence in the nucleus for the fusion proteins. The total amount of cells studied for each construct is equal to $\mathrm{n}$.

\begin{tabular}{|c|c|c|c|c|c|}
\hline Construct & Cytoplasmic & $\begin{array}{c}\text { Percent } \\
\text { Of Cells } \\
\text { with } \\
\text { Cytoplasmic } \\
\text { Fluorescence }\end{array}$ & Nuclear & $\begin{array}{c}\text { Percent } \\
\text { Of Cells } \\
\text { with Nuclear } \\
\text { Fluorescence }\end{array}$ & $\mathrm{n}$ \\
\hline$m 8$ & 22 & $91.67 \%$ & 2 & $8.33 \%$ & 24 \\
\hline$m 8 S_{159} A$ & 26 & $92.86 \%$ & 2 & $7.14 \%$ & 28 \\
\hline$m 8 S_{159} D$ & 19 & $100 \%$ & 0 & $0.00 \%$ & 19 \\
\hline$m 8 S D D D D$ & 32 & $100 \%$ & 0 & $0.00 \%$ & 32 \\
\hline
\end{tabular}

\section{Differences in the Compartmentalization of the Fluorescence}

While there were two cells for both M8 and M8S ${ }_{159} \mathrm{~A}$ that had a preponderance of fluorescence in the nucleus, it became apparent that there was no clearly discerning pattern for where fluorescence was contained within the S2 cells. Four apparent categories arose when observing the fluorescence. The four categories were: a dispersed fluorescence (Figure 15, frame a), fluorescence around the nuclear envelope (Figure 15, frame b), fluorescence at focal points (Figure 15, frame c), and a higher preponderance of fluorescence in the nucleus (Figure 15, frame d). These indicate the diversity of where and how the fluorescence was observed. 


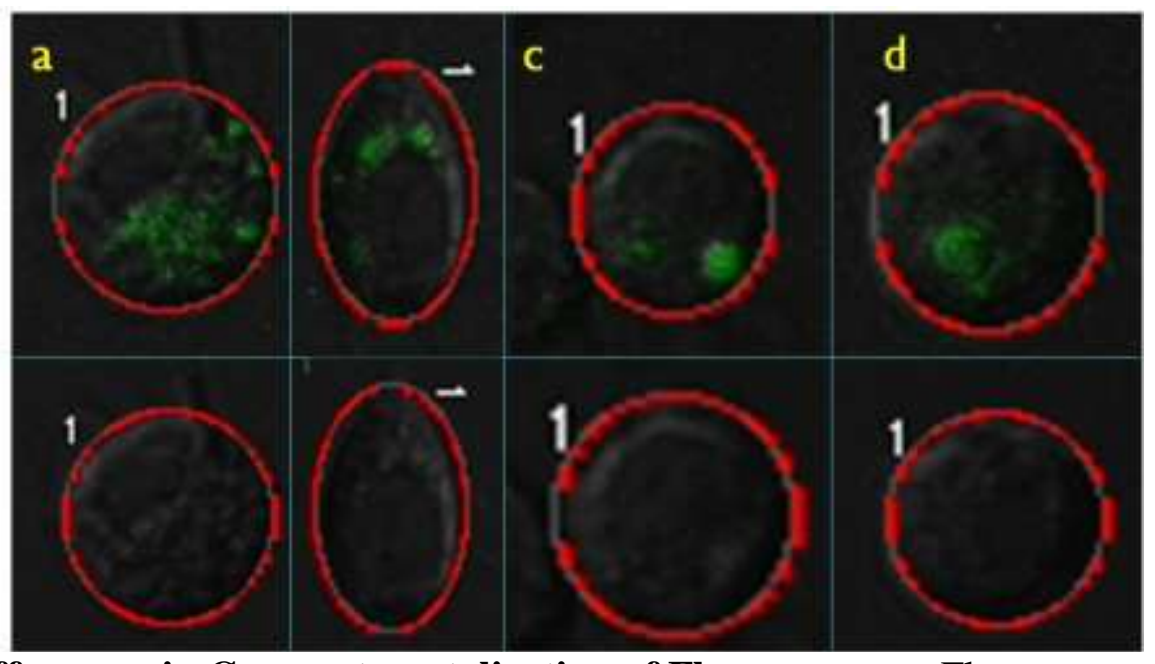

Figure 15- Differences in Compartmentalization of Fluorescence - Fluorescence was observed in differing patterns throughout the cells in the data collection process. No uniform location of fluorescence was observed. Frame a demonstrates a dispersed fluorescence, frame $b$ demonstrates a fluorescence around the nuclear envelope, frame c demonstrates fluorescence defined to a focal point and frame d demonstrates a preponderance of fluorescence in the nucleus. The bottom rows are the same cells above, just with no YFP displayed. 


\section{Discussion \\ Observing Differing Environmental Effects on Growth and Viability}

The intent of this project was to develop a reporter system within S2 cells in order to observe the fluorescently labeled M8 phosphomimetic constructs. In order to accomplish this, it was necessary to determine the optimal temperature to ensure proper maintenance, exponential growth and cellular viability of the cells. This was accomplished by collecting data at differing temperatures and comparing the doubling times and cell viability for the lines created by Schneider in 1972 . His cell lines were grown at $22^{\circ} \mathrm{C}$ and $27^{\circ} \mathrm{C}$ and had doubling times of approximately one-two days (Schneider, 1972).

The doubling times of approximately 27 hours for the cells maintained at $28^{\circ} \mathrm{C}$ and $47-56$ hours for cells maintained at room temperature, control cells (also maintained at room temperature), and $24^{\circ} \mathrm{C}$ indicate rates comparable to Schneider's which were one-two days. These findings indicate that cells incubated at $28^{\circ} \mathrm{C}$ have a rapid growth rate that reaches plateau phase after only 120 hours. The cells grown at room temperature, control cells and $24^{\circ} \mathrm{C}$ have a slower doubling time, but did not reach a plateau point in the study. The gathering of this data helped confirm the choice of maintaining the cells at room temperature, as this doubling time and cellular viability was optimal for experimentation and there was no plateau effect observed at this temperature.

Maintenance of cells at $18^{\circ} \mathrm{C}$ drastically affected their growth rate. Doubling times at $18^{\circ} \mathrm{C}$ slowed to approximately 143 hours. It is well established that the length of Drosophila's life cycle is strongly impacted by culturing conditions, increasing dramatically with lower temperatures. In theory, when working with pluripotent cells in culture from Drosophila, the growth of the cell lines at differing temperatures should mirror fly lines maintained at differing 
temperatures. This corresponded to what was observed in the studies above, especially with the $18^{\circ} \mathrm{C}$ cell line which had a much longer doubling time and slow rate of growth. As indicated by years of research with D. melanogaster, flies maintained at $18^{\circ} \mathrm{C}$ have a complete life cycle from 18-20 days as opposed to flies maintained at $25^{\circ} \mathrm{C}$ which is reduced to 9-10 days (Roberts, 1986).

The data for the cells maintained at $28^{\circ} \mathrm{C}$ followed Schneider's data of a doubling time of approximately one day (Schneider, 1974), once the "plateau" was accounted for (as talked about in the results section). This is a direct correlation of increased cellular activity and doubling time within the cells at higher, yet permissible temperatures. The plateau observed at $28^{\circ} \mathrm{C}$ is typical of a growing cell line, where the cell line reaches a phase where depletion of resources and build up of waste products results in a failure to maintain exponential growth. At this point, the cells in solution begin to die and the growth rate drops. Reaching the plateau at a faster rate would possibly had implications for the co-transfection of the cells, and this is why incubation at $28^{\circ} \mathrm{C}$ was avoided. If the room temperature, $24^{\circ} \mathrm{C}$, and control cells (also at room temperature) from the transfection study were allowed to grow over a greater length of time, the same plateau effect would likely be observed.

There was little effect on cellular viability when cells were maintained at room temperature, $24^{\circ} \mathrm{C}$, and $28^{\circ} \mathrm{C}$, all which display approximately $80 \%$ viability. However, the $18^{\circ} \mathrm{C}$ temperature caused a greater amount of cell death with a viability of around $65 \%$. This could be due to the fact that the optimal temperature for growing $\mathrm{S} 2$ cells is $28^{\circ} \mathrm{C}$, although room temperature also has adequate growth conditions to maintain the cells. Taking these results into consideration, the cells for the transfection study were maintained at room temperature, which gave a consistent cellular viability and doubling rate for the data to be collected. 
Co-transfection had a severe effect on the growth rate and the viability of the cells. Upon transfection a negative correlation for the rate of growth within these cells was observed. This signifies a substantial amount of cell death and a decrease in cellular viability from the onset of the study at $80 \%$, to the end of the study at $20 \%$ ( $0-180$ hours). It is a good assumption that the transfection protocols damaged the cells and caused cell death. When the co-transfected cells were observed with the confocal microscope (96-120 hours after seeding of the cells) there was a cell viability of around $50-60 \%$ based on the trypan blue staining method. This method tests the cell membrane integrity using a large dye molecule (trypan blue) that is excluded from the membrane of living cells and taken in by cells whose membranes have been compromised.

The transfected cells had a severely reduced cellular viability which may have led to the loss of cells over time. This also led to the possibility of a reduced chance of viewing the M8 proteins with the confocal microscope. The protocols of the calcium phosphate transfection that used calcium chloride to bind the DNA in solution and effectively help transport it into the S2 cells seems to interfere with the ability of the cells to live and reproduce. According to Ravid and Freshnay (1998), the Calcium Phosphate Transfection disrupts the cell membrane and can cause cell death. To date, the exact method of how the DNA enters the cell during this transfection is unknown (Ravid and Freshnay, 1998). However, the additional ions in solution possibly creates an environment that is unfavorable for cell growth after transfection. For example, once the transfection occurs, it is believed that the movement of DNA into the cell occurs in two different stages, adsorption and uptake. The adsorption brings the DNA-Calcium precipitate to the cell membrane while the next stage moves the DNA into the cell (Ravid and Freshnay, 1998). This binding of the DNA precipitate could affect the integrity of the cellular membrane causing a high amount of cell death in the transfected cells. 


\section{Creation of the Phosphomimetic $m 8$ Variants}

The fluorescently labeled wild type and phosphomimetic M8 variants were created to be used as molecular tools to help answer various questions as to the cellular location of these proteins within a Drosophila Expression System. Once an established system is created, this would also allow for the possible observation of any of the mutants in an autoinhibitory state which would cause FRET expression. Preliminary tests were run in order to determine whether a significant level of fluorescence was being observed in the treatment cells when compared to the control cells, and secondly to determine data as to the location of the mutant constructs in S2 cells.

\section{Preliminary Data on the Effects of Co-Transfection of $m 8, m 8 S_{159} A, m 8 S_{159} D$ and m8SDDDD Using S2 Cells}

In order to judge whether the individual co-transfections were effective and distinguishable data could be gathered from the system, statistical analyses were performed for each transfection. After determining the average value of fluorescence from cells with no transfection reagents added to them (control 4); the cells within control 1, control 2, control 3, and the treatment groups with a lower fluorescence value than this control 4 threshold value were considered non-transfected and removed from the data. After completion, this indicated that for $\mathrm{M} 8, \mathrm{M}_{159} \mathrm{D}$, and M8SDDDD, the treatment groups did not have significantly higher values of fluorescence than any of the controls (ANOVA and Tukey-Kramer HSD). This indicates that the co-transfection yielded data that is indistinguishable from the control values. For $\mathrm{M}_{8} \mathrm{~S}_{159} \mathrm{~A}$ it was observed that the treatment group cannot be statistically distinguished from control 1 or 2 , but it was distinguishable from control 3 which contained no fluorescent protein. 
Although the preliminary data indicates non-significant differences in the data for M8,

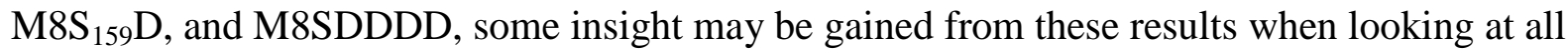
four transfections together (Figure 14). The initial data indicates that control 3, containing pMTGal4 and $\mathrm{CuSO}_{4}$, has consistent fluorescent values (0.4-0.5 intensity/micron $\left.{ }^{2}\right)$ across all four transfections. These cells should contain the lowest values due to the fact that this control does not contain any introduced fluorescent proteins. Looking closer at control 1, it contains a CFP$m 8$-YFP construct and the pMT-Gal4 construct and control 2 contains a $C F P-m 8-Y F P$ construct and $\mathrm{CuSO}_{4}$. Both contain an $m 8$ construct. Higher levels of fluorescence in these controls might be attributed to low level expression of the fluorescent constructs. Leaky expression of the $m 8$ containing constructs could give rise to background levels of fluorescence that is independent of induction by the $\mathrm{Gal} 4$ protein or $\mathrm{CuSO}_{4}$. This is a possible source of the higher levels of fluorescence that was found in these controls.

The failure to get a statistically different fluorescence response in the treatment groups is indicative of a malfunction in the series of events that leads to activation of the target gene. With no overwhelming divergence between the treatment groups and controls, this demonstrates that there is an absence of induction.. There are several possible explanations for this failure which include: $\mathrm{CuSO}_{4}$ levels are incorrect, the UAS and/or the promoters for the $m 8$ constructs have become mutated and are non-functional, the metallothionein promoter has become mutated and is non-functional, the Gal4 protein has become mutated and is non-functional, and finally the M8 proteins are being rapidly degraded and only a few escape this fate. Further analysis will be needed to determine the exact cause behind the low levels of expression.

If induction of the $m 8$ constructs was actually occurring, but could only be significantly

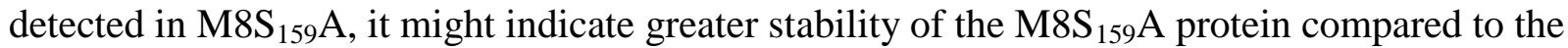


others. Degradation forces such as ubiquitination, and proteolysis could be acting upon the noninhibited forms of M8 (M8, M8S ${ }_{159} \mathrm{D}$, and M8DDDD) causing loss of the fluorescent signaling within the cells. Future studies must support this hypothesis as the data collected on the $m 8 S_{159} A$ transfection are only preliminary. A western analysis would help confirm that the proteins are actually being expressed and could help confirm that M8 and the phosphomimetic proteins are being degraded.

Overall, the conclusions from this experiment are that the transfection of S2 cells did not yield statistically sound data in order to distinguish between the controls and the treatment groups. However, this projects aim was to create constructs and a molecular tool to gain a better understanding of M8's role within S2 cells. This project produced four fluorescently labeled M8 proteins that culminated with data and a method of data collection to determine the value of fluorescence for the various transfections. The lack of statistical differences in the data indicates that this system does need further work in order to be a dependable method to collect data from. Future work needs to determine why the $\mathrm{CuSO}_{4}$ induction failed to activate the target genes. These future studies should use a colorimetric positive internal control such as UAS- $\beta$ galactosidase ( $\beta$-Gal) as a reporter under pMT-Gal4 control. This way if expression of $\beta$-Gal is observed, it would indicate the $m 8$ constructs are not being transcribed, which would indicate a problem with the UAS or promoter regions of the phospomimetic constructs, or that the M8 proteins are not stable. If expression of $\beta$-Gal is not observed, then this would indicate that functional Gal4 is not being produced, which would signify a disruption in the promoter region of the pMT-Gal4 construct, mutation of Gal4, or lack of induction by $\mathrm{CuSO}_{4}$. These tasks shall be explored to examine the failure to induce expression of the target genes. 
As noted above, incorporation of a positive control to ensure that proper induction of Gal4 is occurring must be examined first followed by optimization of the transfection protocol should be pursued. Such modifications to the transfection protocols that have already been examined include changing the DNA concentrations, the molarity of the solutions, and also changing the HeBS solution. These changes seemed to have little effect on the ability to observe a greater number of cells expressing $m 8$. Additional changes that must be looked at include determining if the induction using $\mathrm{CuSO}_{4}$ is contributing to the large amount of cell death and pinpointing the exact cause of the cell death. These, along with other factors within the system must be explored to bring the transformation efficiency to a more workable situation.

\section{Cellular Location of M8, M8S ${ }_{159} A, M 8 S_{159} D$ and M8SDDDD Using S2 Cells}

When examining the preliminary data, no indication as to the location of M8 proteins within a Drosophila cell line could be discerned. However, preliminary data can be observed and certain trends start to emerge when observing the data presented in Table 3 . The majority of the fluorescence produced by the differing M8 proteins was found in the cytoplasm of the cells. However, some of the M8 and M8SA cells had a greater nuclear fluorescence values. Seven percent of the cells showed nuclear fluorescence that was higher than the cytpolasmic fluorescence in M8SA and 8\% for M8.

When looking at the molecular aspects of the Delta-Notch signaling pathway, it is known that Atonal regulates gene expression within the nucleus of the cell, and thus neural fate within the R8 cell. Therefore, it was hypothesized that fully activated M8 with all four phosphorylation sites activated by mutaion (SDDDD) and/or singly mutated (M8SD) would be found in the nucleus regulating Atonal. Once inside the nucleus, these proteins would down-regulate Atonal 
and give rise to a non-neuronal cell. This was not observed in the preliminary data from this study. The data indicate that two out of 28 cells for M8SA had a higher value of fluorescence in the nucleus, suggesting that only the non-phosphorylated form of M8 can enter the nucleus. However, it must be remembered that the data set is very small and this could be attributed to other outside factors that have not been considered.

If phosphorylation truly is the only gate-keeper for nuclear entry, then M8 would have the ability to be found in the phosphorylated and unphosphorylated states as M8 has the capability to be present in either form within the cell. Therefore, it was hypothesized that the majority of fluorescence for this particular construct would not be confined to a single cellular compartment. Preliminary data identify that this was only slightly observed as two cells out of 24 total cells were recognized to have higher nuclear fluorescence rather than cytoplasmic. One possible explanation for this is that the system was saturated with M8 and receptors for M8 within the nucleus are unable to bind M8, therefore excess M8 cannot enter the nucleus. An indication of finding this fusion protein in both cellular compartments is a start to understanding the location of wild type M8.

Finally, if only the specific CK2 phosphorylation site within M8 needed to be phosphorylated to enter the nucleus, then it was hypothesized that M8SD would mainly be located in the nucleus. No nuclear fluorescence was observed for this construct, indicating that phosphorylation may not be required for nuclear localization of M8 and the phosphorylation actually occurs inside the nucleus. Our limited observations might indicate that phosphorylation may preclude the M8 proteins entry into the nucleus. Consistent with that is, the fully phosphomimmetic M8SDDDD was unable to enter the nucleus suggesting that phosphorylation of serine 159 or all four serines inhibits entry into the nucleus. 
As a side note to the above findings, when looking at the fluorescence, there was no consistency in the fluorescence collecting at certain exact locations of the cell for the differing construct or controls. When observed in the cytoplasm, sometimes the fluorescence would be localized to certain focal points, while in other cells there would be a more uniform distribution of fluorescence or a gathering of fluorescence to the nuclear envelope (Figure 15). Other than the two cells that demonstrated a higher nuclear fluorescence value both for M8 and $\mathrm{M}_{8} \mathrm{~S}_{159} \mathrm{~A}$, there was no construct specific patterning in the distribution of fluorescence. This seems to indicate that the fluorescent phosphomimetic constructs have little affinity for a certain spatial positions within the cell and can be observed in the many locations.

While this experiment did gather useful information with regards to the methods and the data gathering, it is understood that a further in-depth study of the localization of these proteins must be preformed once the dilemma of the induction of the target proteins is resolved. In order to take this preliminary data and make the data more reliable and useful, upwards of 50 transfected cells should be examined for each construct. This would be sufficient to help indicate a better trend of cellular fluorescence for each of the constructs. The work presented here lays the foundation for future studies to determine the precise cellular location of M8 variants and possibly autoinhibition and protein-protein interactions 
Chapter Two- Initiating a Novel Drosophila Line to Investigate Position Effect Variegation 


\section{Introduction}

Silencing a gene in any manner can have drastic phenotypic effects for the organism in question. One mechanism for silencing a gene is by compaction into heterochromatin. However, the idea of gene silencing due to the location of a gene in relation to its position to heterochromatin can cause one to question how such a crucial process is regulated. Epigenetics describes gene modifications that alter expression, either silencing them or allowing for expression without changing the underlying DNA sequence. One system that enables scientists to study such a phenomenon is Position Effect Variegation (PEV), which recently has gained a lot of research attention. The studies of PEV have allowed scientists the ability to examine effectors and regulators of heterochromatic gene silencing and what consequence it has on Drosophila genetics.

In order to further understand the occurrence of PEV, one must first delve into the mechanisms of how genes can be silenced due to the structure of chromatin. Chromatin can be found in two differing conformations, open and closed. In its open state, DNA is compacted euchromatin which winds the DNA around a histone octamer (nucleosome) in a looser more open structure. This looser association is due in large part to the presence of acetylated histone octamers (reviewed by Kourzarides, 2007). This type of DNA is readably available to transcription factors interacting with the DNA allowing for gene transcription. The closed state of chromatin is called heterochromatin. In this state, the DNA is tightly packed around the nonacetylated histone octamers (often methylated) and winds back upon itself rendering it closed off to transcription factors. In this state the other transcriptional regulators cannot gain access to the DNA, thus rendering the gene untranscribable and silenced. In PEV, it is these two differing 
states that can dictate whether a gene is active or turned off (as reviewed by Grewal and Moazed, 2003).

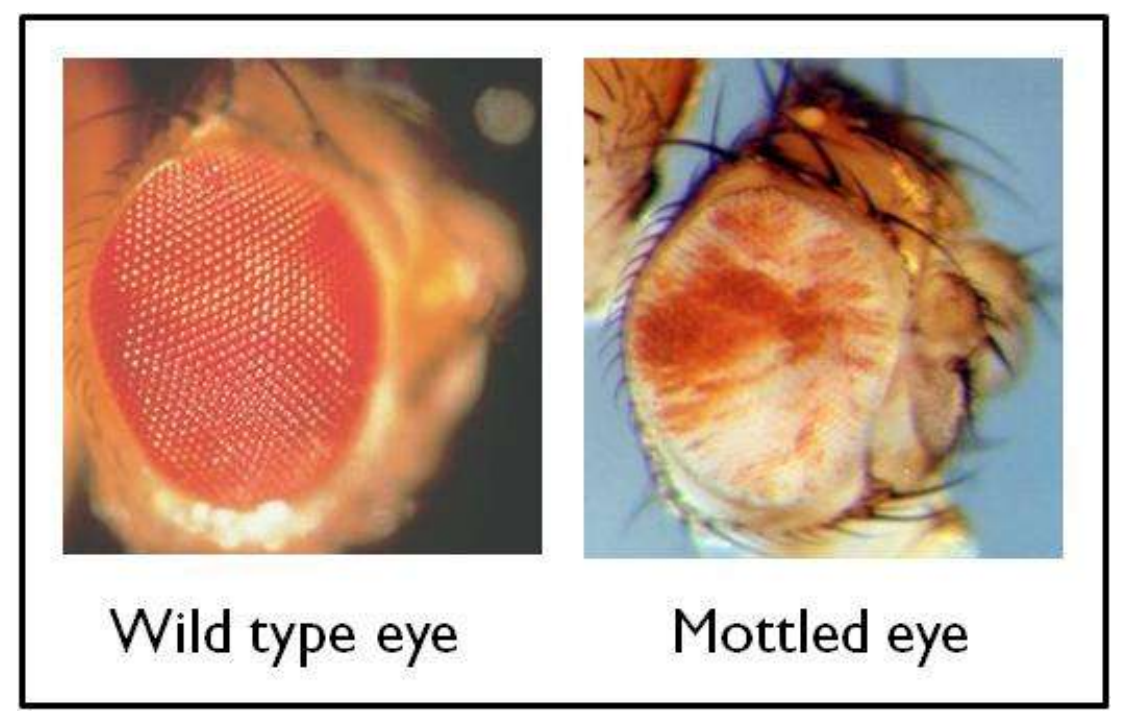

Figure 16: Mottled Phenotype in Drosophila - The left picture displays a wild type Drosophila eye with a functional white gene located in euchromatin. On the right a mottled eye displays gene silencing due to an inversion of the white gene placing it closer to heterochromatin. This inversion causes partial silencing of the gene, also known as Position Effect Variegation (PEV).

$\mathrm{PEV}$ is due to the location of a gene in close proximity to heterochromatin (Wustmann et al., 1989). The silencing occurs when the heterochromatin spreads and masks the expression of the gene in certain cells but not necessarily all cells. This renders the gene partially active in only part of the organism and gives a variegated phenotype. This is observed with the much studied inversion white mottled $4\left(\operatorname{In}(1) w^{m 4}\right)$ flies which present a mottled or speckled red and white eye (Tartof et al., 1984). The molecular reasoning behind this mottling effect is that the white gene, which is responsible for red eye color in Drosophila, has been inverted and is situated adjacent to heterochromatin. This inversion allows for the spreading of heterochromatin to silence the wild type white in certain cells. In Figure 16, red ommatidia are indicative of the wild type white gene expression and white ommatidia indicate where the white gene has been silenced due to the 
heterochromatic compaction and silencing of the gene (Tartof et al., 1984). The use of this visible marker for PEV of a gene will be sought in this project.

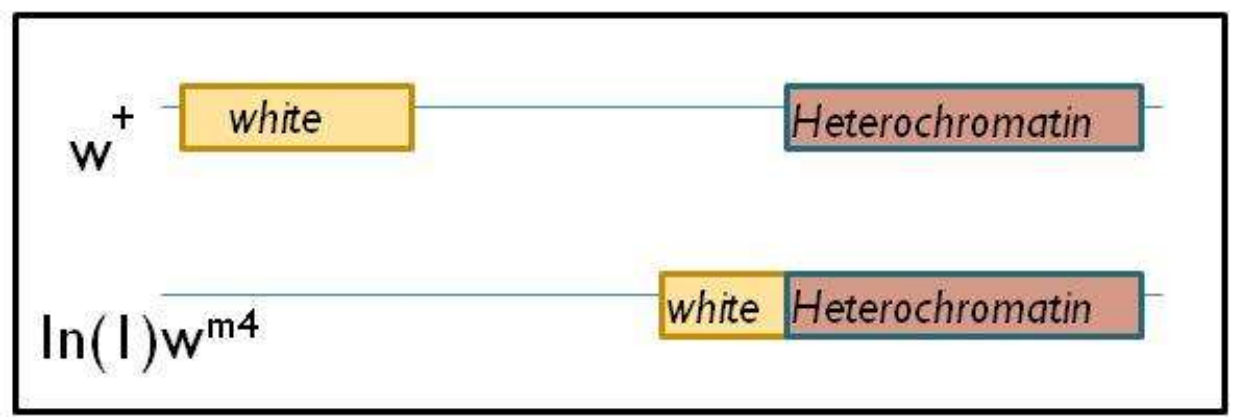

Figure 17: Gene Silencing Due to Position Effect Variegation - In wild type Drosophila the white gene is located in euchromatin and is fully expressed producing a wild type red eye. This inversion of the white gene moves the gene adjacent to heterochromatin. This relocation of the gene along with heterochromatin spreading renders the white gene partially silenced.

Fluorescent proteins have been widely used in research as a visual marker for scientists at a molecular level. They offer a wide range of applications for viewing certain aspects of cells and will be used in this project to view where and when PEV is taking place within Drosophila. It is the aim of this project to create a fluorescent reporter system that mimics the $L a c Z$, reporter system for PEV developed by Lu et al. (1996). In this study, a LacZ marker was driven by a heat shock promoter in order to track where PEV was occurring in differing tissues and at differing developmental time points. To create a similar system, the use of a transgenic construct with a miniwhite gene adjacent to a UAS driven YFP will be used to seek and isolate a PEV mutant that variegates for the easily identifiable white gene. Due to the propensity of hetereochromatin to spread, the adjacent YFP will also be susceptible to PEV. Use of this molecular tool along with a Gal4/UAS driven YFP would give scientists the ability to look at the effects of potential regulators in dealing with gene silencing and not be limited to just the visual phenotype of the white gene. The benefit of using a Gal4/UAS system is that by use of specific drivers, Gal4 can be produced at specific developmental time points and tissues within Drosophila. For instance, 
use of the $\mathrm{P}\{$ GawB $\}$ c684(Bloomington Stock) construct expresses Gal4 only in the wing disc. Such specificity allows scientists to be able to track PEV and modifiers of PEV from the onset of this phenomenon in different tissues and time points.

Rearing the flies at different temperatures has demonstrated that temperature can either enhance or suppress the formation of heterochromatin in Drosophila. At higher temperatures, the formation of euchromatin, or the open state of chromatin is favored, while at lower temperatures, the formation of heterochromatin, or the closed state of chromatin is favored. This has been shown to be due to the acetylation of the histones at higher temperatures which leads to euchromatin and an open state for the DNA (reviewed by Kourzarides, 2007). In order to try to induce heterochromatic silencing, this project will rear flies at different temperatures, mainly lower temperatures such as $22^{\circ} \mathrm{C}$, in order to try and recover a fly with a PEV marker. This will help encourage PEV in flies reared at lower temperatures, thus making the partial silencing of the miniwhite gene easier to spot.

The possibility of obtaining a UAS-driven fluorescent marker of PEV would be significant for studying exactly what modifies PEV. For instance, there is preliminary data that indicates that CK2 modulates PEV (Kouzarides, 2001). CK2 is a key kinase that functions within the cascade of cell fate determination. It, however, is not limited to just this function and has the ability to phosphorylate other proteins at serine/threonine residues. The idea that CK2 modulates PEV is supported by the findings of Zhao and Essenberg (2000) who determined that the Heterochromatin-associated protein 1(HP1), a key non-histone protein that regulates heterochromatin formation, is phosphorylated by CK2 at three serine residues. This direct relationship of $\mathrm{CK} 2$ in the regulation of heterochromatin formation is indicative of a broader necessity to understand how CK2 directly modifies variegation (Zhao and Eissenberg, 2000; 
Grewal and Moazed, 2003). From the tools initiated in chapter one of this thesis, which are helping establish a system to determine the location of M8 in the cell, further applications of this research on PEV, and a better understanding of CK2's function within Drosophila can be obtained.

It is the aim of this project to create a genetic tool to observe PEV in living Drosophila that is not restricted to the eye. Once found, this line of Drosophila can create an opportunity for future research to help determine developmental and external environmental factors that are potential regulators of gene silencing. 


\section{Materials and Methods}

Transgenic lines of Drosophila were created by Swati Banerjee by injection of pUASTattB-YFP DNA into the flies by BestGene Inc. Use of the pUAST-attB construct allowed for the site specific insertion of this DNA at the 2R51D cytological location in the fly genome and control of the YFP by using the Gal4/UAS system. This transgenic line contained a miniwhite reporter gene to allow for visual conformation within the eye of the gene, along with a Yellow Fluorescent Protein attached (labeled YFPminiwhite) found on the second chromosome. Flies were maintained at $24^{\circ} \mathrm{C}$ and crosses were set up to ensure the YFPminiwhite transgenic line was homozygous and that the endogenous white gene had been knocked out.

Once the homozygous YFPminiwhite line was established, 6-72 hour old males were subjected to 3,966 $\pm 0.33 \%$ Rads of gamma radiation using the Gamma cell 1000 irradiator at the WVU Health Sciences Center. Once irradiated, the males were mated with $w ; S c o / C y O$ flies to balance the second chromosome (Banerjee, 2010). The stocks were reared at $24^{\circ} \mathrm{C}, 22^{\circ} \mathrm{C}$ and $18^{\circ} \mathrm{C}$. Parents were cleared from the vials 10 days after initiation of the cross. Offspring were scored based on the variegation of the white gene as an indicator of PEV. Only flies with a variegated eye indicate a partial silencing of the white gene.

Flies with possible variegated eyes were mated back to $w ; S c o / C y O$ flies to ensure the variegation was not an artifact of the radiation process interfering with other genes that are involved within the regulation of eye color. 


\section{Results and Discussion}

Hundreds of crosses were set up in the hopes of developing a molecular tool to observe PEV with a single offspring that variegated for the YFPminiwhite transgene construct. This offspring of interest would correspond to the inversion or translocation of the YFPminiwhite construct being moved closer to a segment of heterochromatin and thus partially silenced due to PEV. Unfortunately, such a fly has yet to be recovered. However, once this fly is discovered, a stable line should be formed by mating it with $w$;Sco/CyO flies. From this point, the determination of the nature (inversion, translocation) of the PEV mutant can be determined by genetic crosses. Once mapped, this miniwhite marker will allow the visual representation of PEV within the eye. However this projects aim was to isolate a fly with YFP as a marker of PEV which will not be limited to just the eye. Once established, YFP, under control of the Gal4/UAS system, can be visualized in other locations of the fly. Specific drivers for different time points within the development of the fly can be observed along with specific types of tissues to determine different forces that modulate PEV. This will create a useful tool for future work studying the implications of how CK2 modulates the regulation PEV.

Such studies shall include further analysis of not only internal regulation of certain effectors that can influence CK2, but also differing environmental factors that can influence CK2 and the regulation of heterochromatic gene silencing within specific tissues and time points (Kouzarides, 2007). According to preliminary studies, it has been observed that CK2 modulates and regulates PEV within Drosophila. This is consistent with the finding that CK2 phosphorylates HP1 which regulates heterochromatin formation (Zhao and Eissenberg, 2000). Implications of such research indicate that further studies can help identify the modifiers of chromatin remodeling to help reduce gene silencing due to external and internal forces. A better 
understanding can help lead to treatments for diseases that are thought to be caused by PEV such as X-Linked deafness, Greig cephalopolysyndactyly, and Sex reversal. These diseases are thought to have been caused by PEV of their related genes POU3F4, GLI3, and SRY. It shall be noted that these diseases are only observed where one allele's reduced expression can lead to changes in phenotypes (Kleinjan and Heyningen, 1998). Such findings can lead to better diagnosis and care for these treatments.

Although no flies with mottled eyes were recovered throughout the duration of the experiment, other mutations were observed indicating that the radiation was working. These mutations, such as a reduced eye size and an orange eye color, indicate that the sperm were successfully mutated. This project shall be continued by future graduate students, as the possible outcomes and future research such as environmental and molecular modifiers of PEV in vivo will be studied. The establishment of this novel line of flies will help capture a better understanding of how $\mathrm{CK} 2$ and other modifiers can regulate expression of a gene in an epigenetic manner. 


\section{References}

Akazawa, C., Sasai, Y., Nakanishi, S., Kageyama, R., 1992. Molecular Characterization of a Rat Negative Regulator with a Basic Helix-Loop-Helix Structure Predominantly Expressed in the Developing Nervous System. The Journal of Biological Chemisty. 267, 2187921885 .

Artwell, B., Kridemann, P., Turnbull, C. Plants in Action. Melbourne: Macmillan Education Australia Pty Ltd, 1999.

Bailey, A., Posakony, J., 1995. Suppressor of Hairless directly activates transcription of Enhancer of split Complex genes in response to Notch receptor activity. Genes and Development. 9, 2609-2622.

Baker, N., 2004. Atonal Points The Way- Protein-Protein Interactions and Developmental Biology. Dev Cell. 7, 632-634.

Banerjee, S. 2010. "Analyzing The Role of CK2 and PP2a in Drosophila Position Effect Variegation.” MS Thesis. West Virginia Universisty, Morgantown, 2010.

Bose, A., Kahali, B., Zhang, S., Lin, J., Allada, R., Karandikar, U., Bidwai, A., 2006. Drosophila CK2 regulates lateral-inhibitino during eye and bristle development. Mechanisms of Development. 123, 649-664.

Doroquez, D., Rebay, I., 2006. Signal Integration During Development: Mechanisms of EGFR and Notch Pathway Function and Cross-Talk. Critical Reviews in Biochemistry and Molecular Biology. 41, 339-385.

Fischer, A., and Gessler, M. 2007. Delta-Notch- and then? Protein interactions and proposed modes of repression by Hes and Hey bHLH factors. Nucleic Acids Research. 35, 45834596.

Fortini, M, Rebay, I., Caron, L., Artavanis-Tsakonas, S. 1993. An activated Notch receptor blocks cell-fate commitment in the developing Drosophila eye. Nature. 365, 555-557.

Frankfort, B., and Mardon, G. 2002. R8 development in the Drosophila eye: a paradign for neural selection and differentiation. Development. 129, 1295-1306.

Giebel, B., Campos-Ortega, J., 1997. Functional dissection of the Drosophila Enhancer of split protein, a suppressor of neurogenesis. Developmental Biology. 94, 6250-6254.

Greenspan, R., 1990. The Notch, adhesion, and developmental fate in the Drosophila embryo. New Biology. 7, 595-600.

Grewal, S., Moazed, D. 2003. Heterochromatin and Epigenetic Control of Gene Expression. Science. 301, 798-802. 
He, L., Olson, D., Wu, X., Karpova, T., McNally, J., Lipsky, P., 2003. A Flow Cytometric Method to Detect Protein-Protein Interaction in Living Cells by Directly Visualizing Donor Fluorophore Quenching During CFP-YFP Fluorescence Resonance Energy Transfer (FRET). Cytometry Part A. 55A, 71-85.

Jan, Y., Jan, L., 1994. Genetic control of cell fate specification in Drosophila peripheral nervous system. Annual Review Genetics. 28, 373-393.

Karandikar, U., Trott, R., Yin, J., Bishop, C., Bidwai, A., 2004. Drosophila CK2 regulates eye morphogenesis via phosphorylation of E(spl)m8. Mechanisms of Development. 121, 273-286.

Kleinjan, D., Heyningen, V., 1998. Position effect in human genetic disease. Human Molecular Genetics. 7, 1611-1618.

Kouzarides, T., 2007. Chromatin Modification and Their Function. Cell. 128, 693-705.

Lesokhin, A., Yu, S., Katz, J., Baker, N., Several Levels of EGF Recepter Signaling during Photoreceptor Specification in Wild-Type, Ellipse, and Null Mutant Drosophila. Developmental Biology. 205, 129-144.

Ligoxygakis, P., Yu, S., Delidakis, C., Baker, N., 1998. A subset of Notch functions during Drosophila eye development require $S u(H)$ and the $E(s p l)$ gene complex. Development. 125, 2893-2900.

Lu, B., Bishop, C., Eissenberg, J. 1996. Developmental timing and tissue specificity of heterochromatin-mediated silencing. The EMBO Journal. 15, 1323-1332.

Nakao, K., Campos-Ortega, J., 1996. Persistant Expression of Genes of the Enhancer of Split Complex Suppresses neural Development in Drosophila. Neuron. 16, 275-286.

Paroush, Z., Finley, R., Kidd, T., Wainwright, M., Ingham, P., Brent, R., Horowicz, D., 1994. Groucho is required for Drosophila neurogenesis, segmentation and sex determination and interacts directly with hairy-related bHLH proteins. Cell. 79, 805-815.

Patterson, G., Dayand, R., Piston, R., 2001. Fluorescent protein spectra. Journal of Cell Science. $114(5), 837-838$.

Ravid, K. and Freshney, I. DNA Transfer to Cultured Cells. New York: Wiley-Liss, Inc, 1998.

Roberts, D. Drosophila a Practical Approach. Washington, D.C.: IRL Press, 1986. 
Sasai, Y., Kageyama, R., Tagawa, Y., Shi, R., Nakanishi, S., 1992. Two Mammalian HelixLoop-Helix Factors Structurally Related to Drosophila Hair and Enhancer of Split. Genes Dev. 6, 2620-2634.

Schneider, I. 1972. Cell Lines Derived From late Embryonic Stages of Drosophila melanogaster. Journal of Embryology. 27, 353-365.

Tartof, K., Hobbs, C., Jones, M. 1984. A structural basis for variegating position effects. Cell 71, 869-878.

Trott,R., Kalive, M., Paroush, Z., Bidwai, A., 2001. Drosophila melanogaster Casein Kinase II Interacts with and Phosphorylates the Basic Helix-Loop-Helix Proteins m5, m7, and m8 Derived from the Enhancer of split Complex. The Journal of Biological Chemistry. 276, 2159-2167.

Wustmann, G., Szidonya, J., Taubert, H., Reuter. 1989. The genetics of position-effect variegation in Drosophila melanogaster. Molecular Genetics. 217, 520-527.

Zhao, T., Heyduk, T., Allis, D., Eissenberg, J. 2000. Heterochromatin Protein 1 Binds to Nucleosomes and DNA in vitro*. The Journal of Biological Chemistry. 275, 2833228338. 